US Army Corps

of Engineers $S_{\circledast}$

Engineer Research and Development Center

\title{
Image Data Acquisition System User's Guide and Technical Documentation
}

Charles D. Hahn and Jerrell R. Ballard, Jr.

September 2001 
The contents of this report are not to be used for advertising, publication, or promotional purposes. Citation of trade names does not constitute an official endorsement or approval of the use of such commercial products.

The findings of this report are not to be construed as an official Department of the Army position, unless so designated by other authorized documents. 


\section{Image Data Acquisition System User's Guide and Technical Documentation}

by Charles D. Hahn, Jerrell R. Ballard, Jr.

Environmental Laboratory

U.S. Army Engineer Research and Development Center 3909 Halls Ferry Road

Vicksburg, MS 39180-6199

Final report

Approved for public release; distribution is unlimited

Prepared for U.S. Army Corps of Engineers

Washington, DC 20314-1000

under Geospatial Research and Development Program 


\section{Contents}

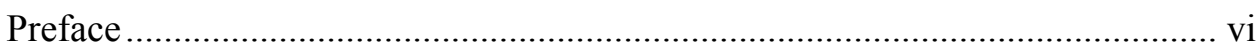

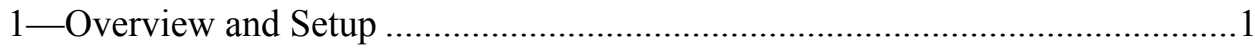

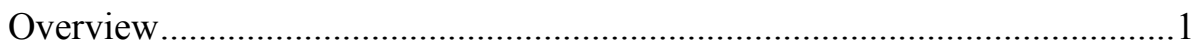

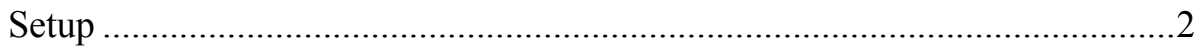

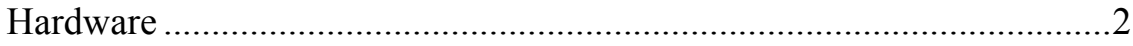

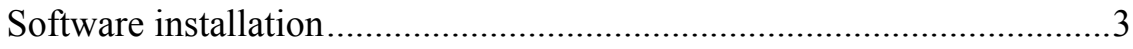

2-Data Acquisition and Processing Software ..................................................5

Data Acquisition Software ....................................................................

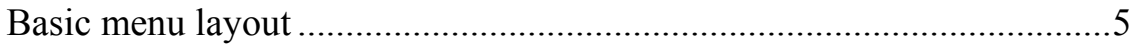

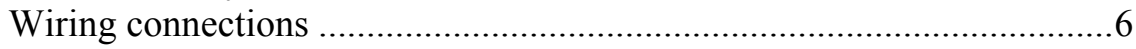

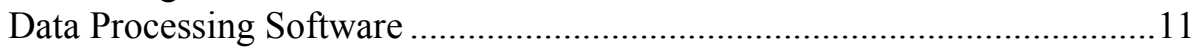

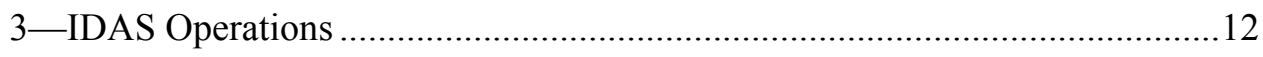

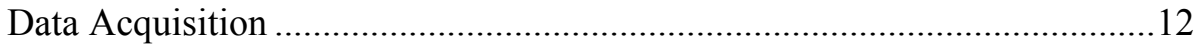

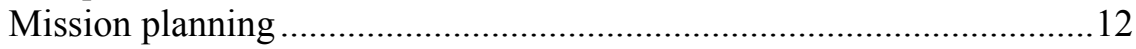

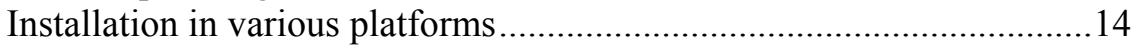

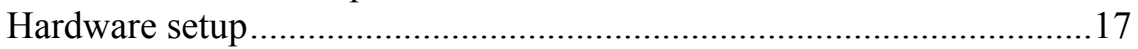

IDAS Data Acquisition Program configuration and operation ...............17

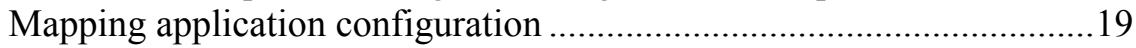

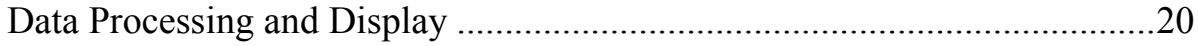

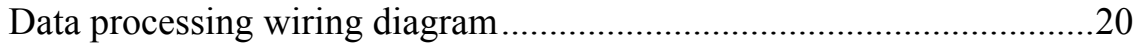

Data processing application instructions .............................................21

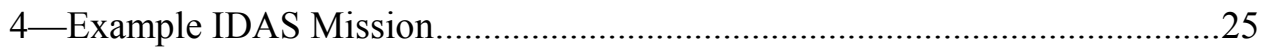

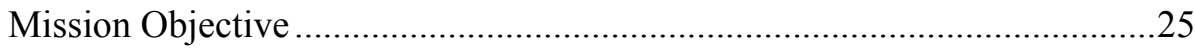

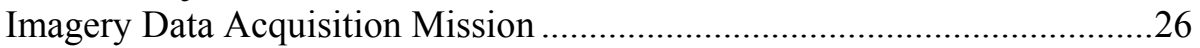

Imagery Data Processing and Display ..................................................... 30

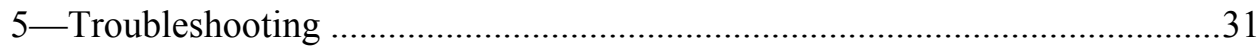


Appendix A: Description of Data Acquisition Hardware

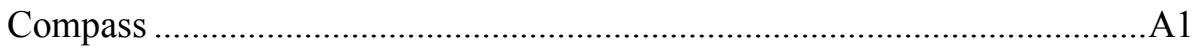

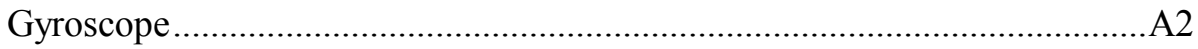

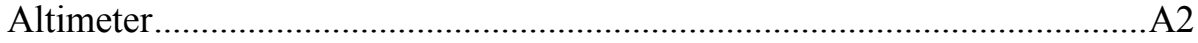

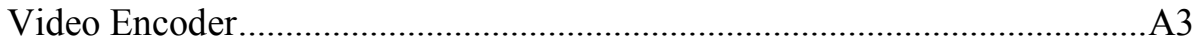

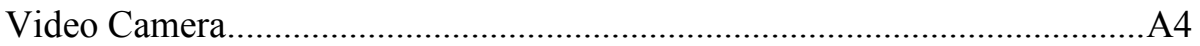

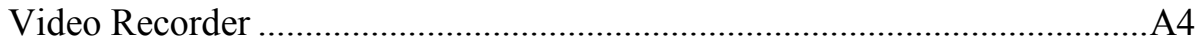

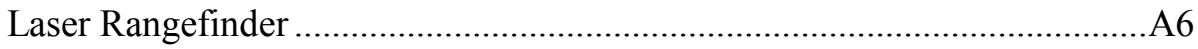

Appendix B: Accuracy Assessment..................................................................

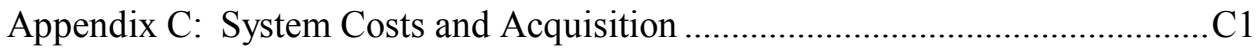

SF 298

\section{List of Figures}

Figure 1. Serial port selection box............................................................

Figure 2. Basic menu layout .....................................................................6

Figure 3. 110-V a-c connections ............................................................. 7

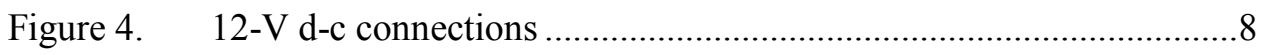

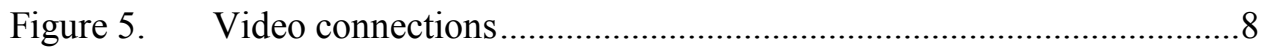

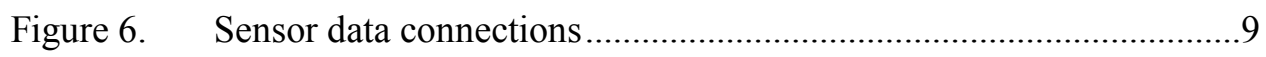

Figure 7. Audio connections..................................................................... 10

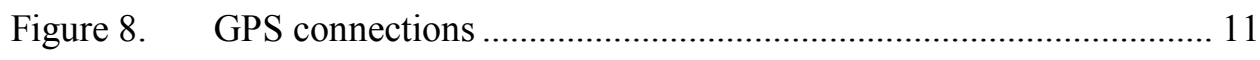

Figure 9. IDAS video equipment in an aircraft........................................... 14

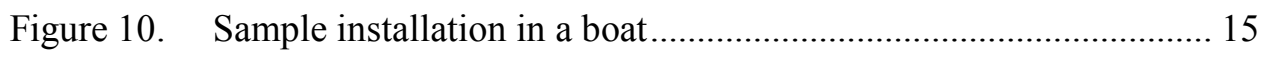

Figure 11. Sample installation in a ground vehicle.......................................... 15

Figure 12. Data collector configuration menu ............................................ 17

Figure 13. Compass calibration confirmation ............................................... 18

Figure 14. Data processing schematic ......................................................... 19

Figure 15. IDAS data processor display application........................................ 20

Figure 16. Menu for ArcView IDAS start up.............................................. 21 
Figure 17. Prompt to append to or create new point data file.

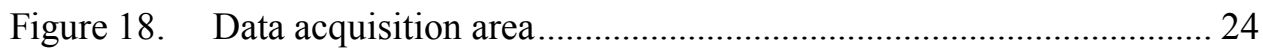

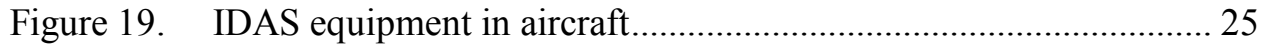

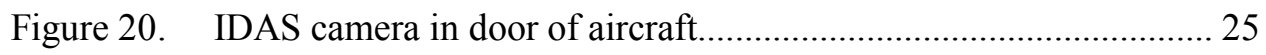

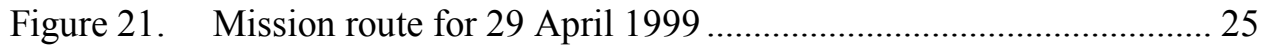

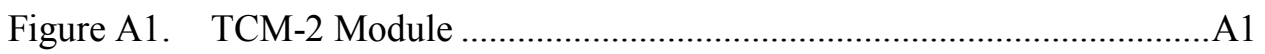

Figure A2. MOLX Connector One TCM-2 …...............................................

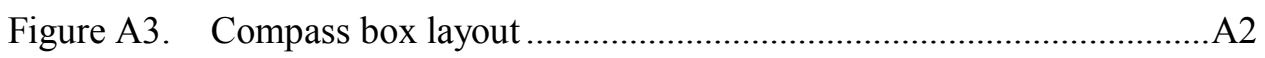

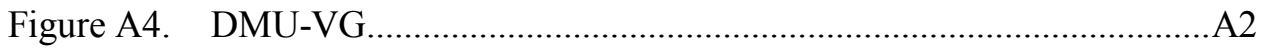

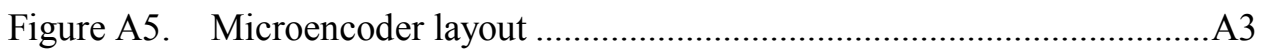

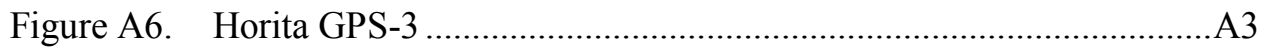

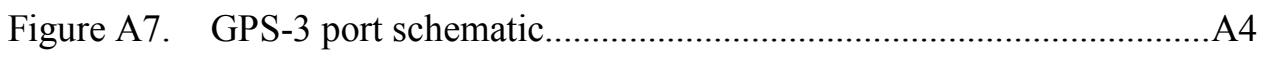

Figure A8. Sony CCD-TR700 and Panasonic AG-5700 ….............................A4

Figure A9. AG-5700 switches and input and output ports ..............................A5

Figure A10. Laser Atlanta Advantage Laser .......................................................A6

Figure A11. Example of Laser Atlanta custom laser .........................................A6 


\section{Preface}

The Image Data Acquisition System (IDAS) was initially developed by the U.S. Army Engineer Research and Development Center (ERDC) Environmental Laboratory (EL), Vicksburg, MS, in 1995 to help fill a need for a cost-effective image data acquisition system to provide data for monitoring erosion along the upper Mississippi River. During the period 1997-1998, under the Geospatial Research and Development Program, the IDAS was improved to allow collection of geo-referenced imagery for Corps of Engineers activities. The Technical Monitor for the Geospatial Research and Development Program was Mr. M. K. Miles, CECW-P, and the remote sensing program manager was Mr. Timothy Pangburn, CECRL-RS, ERDC Cold Regions Research and Engineering Laboratory, Hanover, NH.

IDAS is an instrumented video/image data acquisition system. It uses realtime differential Global Positioning System (GPS) to measure the camera location, then couples that information with data from geometry sensors (digital compass, gyroscope, and altimeter) to later calculate the location of the center of the field of view in the terrain. It can be mounted in various platforms including aircraft, boats, and automobiles. It can be used to collect imagery along linear features such as roads, rivers, or shorelines; to identify and locate point features such as structures, rapidly eroding areas along riverbanks, or problem areas in a levee system; to update information in a Geographic Information System (GIS) database about erosion control structures such as weir dams or lengths of armored shoreline; and to inventory other man-made structures along the shoreline of a lake or reservoir. IDAS may also be configured with other imaging sensors (such as infrared imagers) to further expand its applications.

Mr. Charles D. Hahn, Environmental Systems Branch (ESB), Ecosystems Evolution and Engineering Division (EEED), EL, was principal investigator for this program. Guidance was provided by Dr. M. Rose Kress, ESB, and Mr. Harold W. West, Chief, ESB. The study was conducted under the general supervision of Dr. David J. Tazik, Chief, EEED, and Dr. Edwin Theriot, Acting Director, EL. Mr. Hahn was responsible for the development of the IDASDataAc program. Mr. Jerrell R. Ballard, Jr., ESB, was responsible for developing the IDAS_Decode application. Mr. Hahn and Mr. Ballard prepared this report. 
At the time of publication of this report, Dr. James R. Houston was Director of ERDC, and COL John W. Morris III, EN, was Commander and Executive Director.

This report should be cited as:

Hahn, C. D., and Ballard, J. R., Jr. (2001). ì Image Data

Acquisition System (IDAS) userís guide and technical

documentation,î ERDC/EL TR-01-27, U.S. Army Engineer

Research and Development Center, Vicksburg, MS.

The contents of this report are not to be used for advertising, publication or promotional purposes. Citation of trade names does not constitute an official endorsement or approval of the use of such commercial products. 


\section{Overview and Setup}

\section{Overview}

The Image Data Acquisition System (IDAS) is an instrumented video data collection and processing system for collecting oblique geo-referenced imagery. IDAS can be deployed in a variety of platforms (aircraft, boats, and ground vehicles), using a variety of imaging sensors. Any sensor providing an RS-170 output can be used to provide imagery for IDAS. IDAS imagery can be used to describe/interpret and locate features in almost any terrain type (rivers, lakes, forested areas, grasslands, rangelands, agricultural fields, etc.) for use in Geographic Information System (GIS) databases. The imagery may also be used to characterize features already in the GIS database, such as levees, riverbanks, and shorelines, or to update information contained in the database. The system can also be used to document man-made structures in disaster-prone areas such as floodplains. Because the system is small and portable, it can be deployed quickly to assess conditions after floods, earthquakes, hurricanes, or other natural disasters. Imagery is ready for analysis immediately upon return; or if a more rapid analysis is required, an onboard analyst may examine the imagery real-time. The integrated Global Positioning System (GPS) uses real-time differential processing to provide real-time positioning without the need for extensive ground control. Directional sensors mounted with the cameras measure and record the viewing geometry for approximate positioning of features observed in the imagery. An altimeter is included to provide altitude reference. Analog imagery provides for rapid analysis with minimal hardware requirements. Imagery may also be digitized for more detailed computer analysis or for on-line documentation of the features examined with IDAS. All data required for analysis are recorded on video tape to provide a complete, one-piece record of the mission(s). IDAS can also record audio annotations and observations made during the mission to note special features of interest.

IDAS has been used to document erosion and bank stabilization projects along the Illinois, Mississippi, and Missouri Rivers; to document boat docks and piers on public lakes and reservoirs; and to detect and monitor problems in the main-line levees along the Mississippi River during peak flood events. IDAS has also been used to document structures in flood-prone areas and to plan more detailed surveys in those areas. The system has also been used to map and document airboat trails around Fairbanks, Alaska. 


\section{Setup}

\section{Hardware}

IDAS hardware is composed of three major subsystems: basic video hardware (recorder, monitor, and video encoder), data acquisition hardware (sensors, GPS receiver, notebook computer, and video source), and data processing hardware (video capture device). Each of these subsystems is described in the following paragraphs.

Basic video hardware. The basic video hardware consists of a monitor, video recorder, and video encoder/decoder. During data acquisition, the video encoder/decoder receives the position and time data from the GPS receiver and the geometry and altitude data from the other sensors and mutliplexes that record information in the time code or audio portion of each video frame. During data processing, the video encoder/decoder decodes that information from the video frames and transmits it to the computer. The video recorder currently used is a Panasonic AG-5700. This is a Super VHS- (SVHS-) capable unit with dual audio channels, which allow for the simultaneous recording of the data along with verbal information recorded during the mission. A monitor is required to view the imagery during data collection as well as during data processing. It can be a Cathode Ray Tube (CRT) type monitor, a flat panel Liquid Crystal Display (LCD) monitor, or computer-video ì monitorî software. The CRT type monitors provide clearer displays and faster responses but are larger and require more power than the other two types of monitors. If SVHS recordings are necessary, then a pair of SVHS-to-chroma/lumina splitters are necessary. These are simple cable devices that separate the chroma and lumina wires from the SVHS cable and provide bayonet Neil-Concelman (BNC) connections for each signal. The AG-5700 record provides output on the output composite video port as well as on the SVHS port when in SVHS operation. Therefore, during data collection, these adapter cables are unnecessary. Monitor output can be taken directly from the composite video port to the encoder and monitor.

Data acquisition hardware. In addition to the basic video hardware, the data acquisition subsystem contains the video source (video camera or composite video output of another sensor or imager), a digital compass, a solid-state digital gyroscope, a digital altimeter, and a GPS receiver. The GPS receiver must be capable of providing National Maritime Electronics Association (NMEA) 0183 output, specifically the GGA string. The GGA string provides position and time as well as some other measures of position quality. The video encoder uses this string to extract the position and time information from the GPS position data. The GPS receiver also provides the position data to mapping software on the notebook computer. The digital compass is used to measure the heading in which the cameras are pointed (not vehicle direction), and the gyroscope is used to measure the vertical or tilt angle of the camera. The altimeter is used to measure the altitude of the platform (aircraft or ground vehicle). Each of these instruments interfaces to the notebook computer (described next), which processes the raw sensor data and reformats it for output to the video encoder. The compass and the gyroscope are mounted with the camera so that any changes 
of the camera are duplicated by these sensors. The altimeter is mounted separately and is used to provide a more accurate and stable altitude than the GPS can provide. The notebook computer used for the data acquisition system is a 233-MHz Pentium II notebook with a 4-GB hard disk. The data collector software requires four serial ports, which are in addition to the main serial port (COM1). These additional four ports are supplied by using a third-party Personal Computer Memory Card International Association (PCMCIA) card. The card used for this installation is the Quatech QSP-100. To identify the proper serial ports on this card, the manufacturer labels the connectors as Ports A-D. Port A is the first port provided by this card (COM5), and port $\mathrm{D}$ is the last port provided by this card (COM8).

For this application, the compass used was the Precision Navigation TCM-2 compass module. The gyroscope selected was the Crossbow DMU-VG. The altimeter was the Rocky Mountain Instrument Microencoder. The GPS receiver used was the Trimble Navigation Pathfinder Pro-XRS, which is capable of receiving and processing real-time differential corrections from either the U.S. Army Corps of Engineers (USACE)/U.S. Geological Survey (USGS) navigation beacons or the Omni Star satellite based correction source. The mapping software used during data acquisition is Delormeís Street Atlas; however, several other packages are available including Delormeís Topo USA product, Geolink, and Environmental Systems Research Instituteís (ESRIís) Tracking Analyst. The IDAS equipment is described in detail in Appendix A.

Data processing hardware. IDAS requires specialized computer hardware and software for proper system operation. The minimum hardware requirements are a computer running Windows 98 with at least a 400-MHz Pentium II CPU, 128 MB RAM, CD-ROM drive, 6 GB of disk space, video-signal capable (Composite and S-Video signals) display card, and a 16-bit 17-in. color graphics monitor.

The GIS used with IDAS is ESRI ArcViewÆ. ESRI Avenue code is utilized for data processing.

It is recommended that the end user of the data processing of IDAS imagery be trained and well acquainted with the operation of ArcView and have a technical understanding of geographic information concepts. ESRI provides several training courses during each year at locations nationwide (http://www.esri.com).

\section{Software installation}

Data acquisition software. After installing the serial port card and its software and drivers, create a folder to store the data acquisition program and copy the program IDASDataAc.EXE from the installation floppy to that folder. Do not cut the file from the floppy and paste in the new folder as this will erase the file from the installation floppy. Then right-click on the file in the folder on the hard disk and select ì Create Short-Cut.î Click on the short cut and drag it to 
the desktop. After closing any open windows, double click on the IDASDataAc icon to start the program. Select the configure option and select one of the instruments. A window similar to the one shown in Figure 1 should appear showing all of the serial ports installed.

The IDASDataAc.EXE program scans the computer for all available serial ports, and it will reveal if the multiport card is properly installed. In this system, COM1 is the main system serial port, COM2 is a modem, COM4 is the IR port, and COM58 are on the multiport card (COM3 is not installed on this particular system). The ports shown on the computer may differ based on the system configuration and the card used. If five serial ports are not listed, please reinstall the drivers for the multiport card according to the manufacturerís instructions. The data

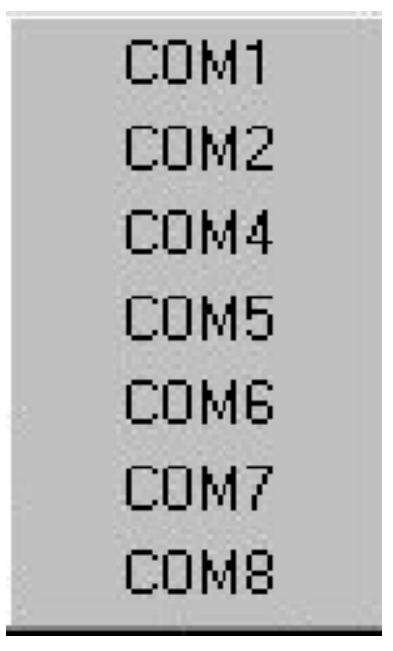

Figure 1. Serial port selection box acquisition software has now been successfully installed. The data acquisition system (hardware and software) requires a minimum of five available RS-232 ports. Modem and IR ports are not suitable for this application. These ports appear in the menu because the software cannot distinguish ports provided by a modem or IR device from normal serial ports.

Data processor software installation. The IDAS extension for ArcView must be installed in the $\$ A V \_H O M E l a v \_g i s 30 \backslash$ arcviewlext32 directory. Copy the extension file (idas.avx) from the distribution media into this directory. Start up ArcView. Load the extension using the EXTENSIONS dialog under the FILE pulldown menu. Select and load the IDAS Extension. Find where the extension is listed and place a check in the box. Then press the OK button on the EXTENSIONS dialog to load the extension. The extension will load itself into ArcView and is now ready for use. 


\section{Data Acquisition and Processing Software}

The IDAS system is uniquely designed to acquire oblique imagery along linear features such as rivers, roads, or levees. Imagery can also be collected on point features such as structures, seeps, or boils in levees during peak flood events, or similar features along a linear path (roads, rivers, power lines, firebreaks, etc). IDAS may be used for collecting imagery of selected points within a two-dimensional area; however, other remote sensing systems may be more suitable depending on the application.

\section{Data Acquisition Software}

There are two aspects for the data acquisition software. The first is the mapping program. Delormeís Street Atlas Version 6.0 is currently used, and the setup and operation are fully explained in the documentation that accompanies that software. The other software is the IDASDataAc program. This program integrates data from the compass, gyroscope, and altimeter and outputs it to the video encoder so that it can be encoded with the position information on the video tape.

\section{Basic menu layout}

The basic menu for the IDASDataAc program, shown in Figure 2, resembles most Windows program menus. The pulldown menus are FILE, CONFIGURE, and HELP. The FILE menu contains the options to calibrate the digital compass, start the sensor interrogation, suspend sensor interrogation, and exit the application. The CONFIGURE menu is used to identify the serial ports connected to the various sensors and outputs. The HELP option is not implemented in this release (Version 1.0). The edit boxes (white boxes on main display) immediately to the right of the titles (AZIMUTH, TILT, PITCH, ALTITUDE, AND OUTPUT) show the processed sensor values (or the output string). The other edit boxes monitor the actual sensor inputs and are used to verify proper sensor operation. Changing values in these boxes indicate that sensor outputs are being generated. The buttons at the top right corner maintain their normal Windows functions (SHRINK TO TASKBAR, MAXIMIZE, AND CLOSE). 


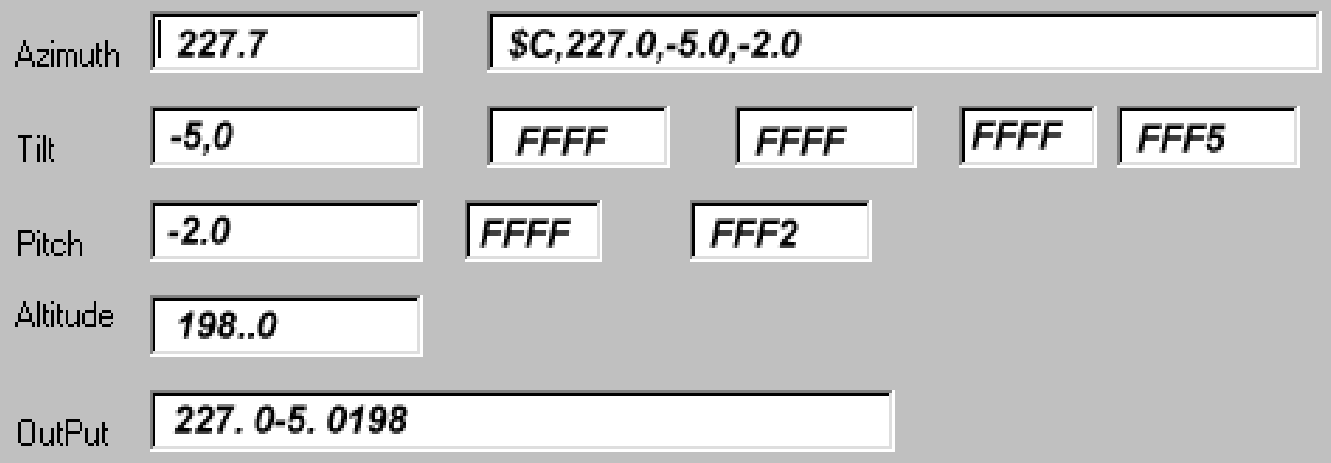

Figure 2. Basic menu layout

\section{Wiring connections}

Connecting IDAS is straightforward. It is simplest to work with one signal (or cable) at a time. For the purposes of these instructions, ì connectorî refers to the physical connector (DB-9, BNC, SVHS) on the wire. ì Portî refers to the connection on the equipment (Video In, Video Out, etc.). The following six steps are used to set up the IDAS data acquisition hardware:

a. Step 1. In most platforms, $110-\mathrm{V}$ a-c power may be supplied using a $12-\mathrm{V}$ d-c to $110-\mathrm{V}$ a-c inverter. Some aircraft may not have $12-\mathrm{V}$ d-c power available, so it will be necessary to use the appropriate inverter to supply the $110-\mathrm{V}$ a-c power. Make all $110-\mathrm{V}$ power connections shown in Figure 3. Starting with inverter and power strip (labeled 110-V a-c), connect power for cameras, recorders, and computer to the power strip. If a $110-\mathrm{V}$ monitor is used, make these connections. If a $24-\mathrm{V} \mathrm{d}-\mathrm{c}$ inverter is used, a $12-\mathrm{V} \mathrm{d}$-c power supply will be required for the sensor equipment. If a $12-\mathrm{V} \mathrm{d}-\mathrm{c}$ inverter is used, then the sensor equipment can be connected in parallel. 

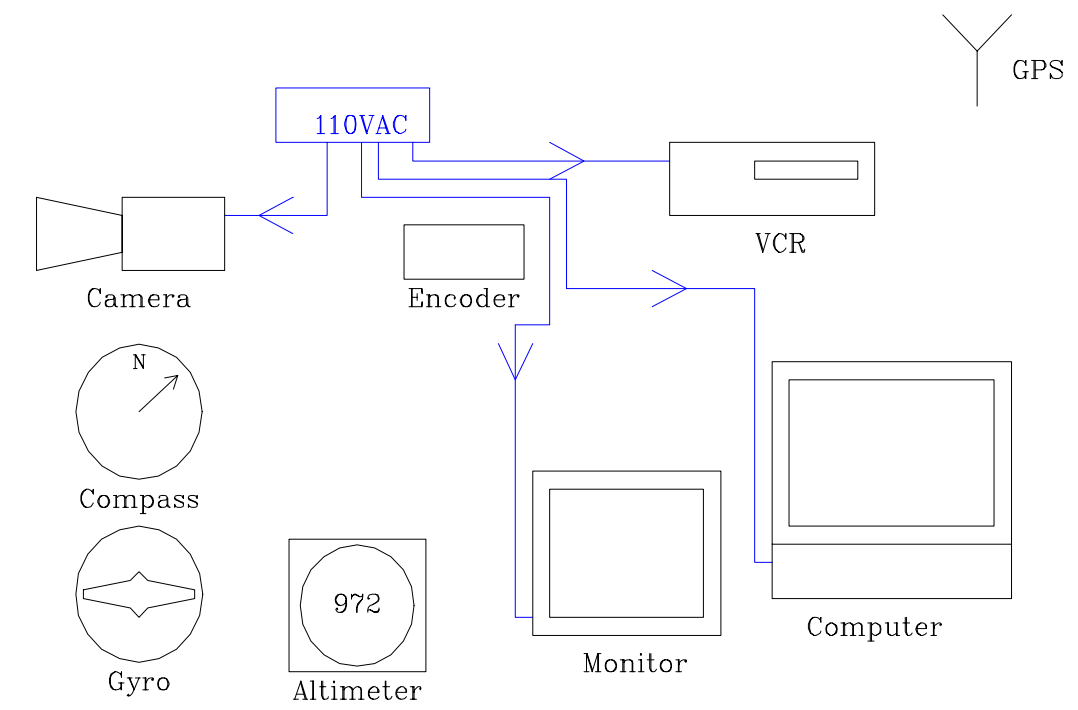

Figure 3. 110-V a-c connections

b. Step 2. IDAS requires $12-\mathrm{V}$ d-c power for the sensors and the encoder. If the platform has $12-\mathrm{V} \mathrm{d}-\mathrm{c}$ power available, then these connections may be made in parallel with the 110-V a-c inverter described in Step 1. If $12-\mathrm{V} \mathrm{d}-\mathrm{c}$ power is not available, then it will be necessary to add a $12-\mathrm{V} \mathrm{d}$ c power supply to the system. This can be either a $110-\mathrm{V}$ a-c or $12-\mathrm{V}$ d-c power supply such as the ones available from electronics supply stores. Make the 12-V d-c cable connections as shown in Figure 4.

c. Step 3. Make the three video connections as shown in Figure 5, starting with the camera. If SVHS equipment is being used, an adapter to separate the chroma and lumina signals in the SVHS cable will be required to connect the video encoder. Connect the lumina signals to the Video In port on the encoder. A similar adapter will be required to connect the encoder to the recorder. Connect the Video Out from the encoder to the lumina connector on the adapter. The chroma signal is connected straight through both adapters. The SVHS connector is then attached to the SVHS Video In port on the recorder. It may be less complicated to make the connection from the camera to the recorder first. Using the composite video output, connect the recorder to the video encoder. Next, connect the video encoder to the monitor, using the composite video input. This allows the operator to monitor the time code to ensure proper function. 


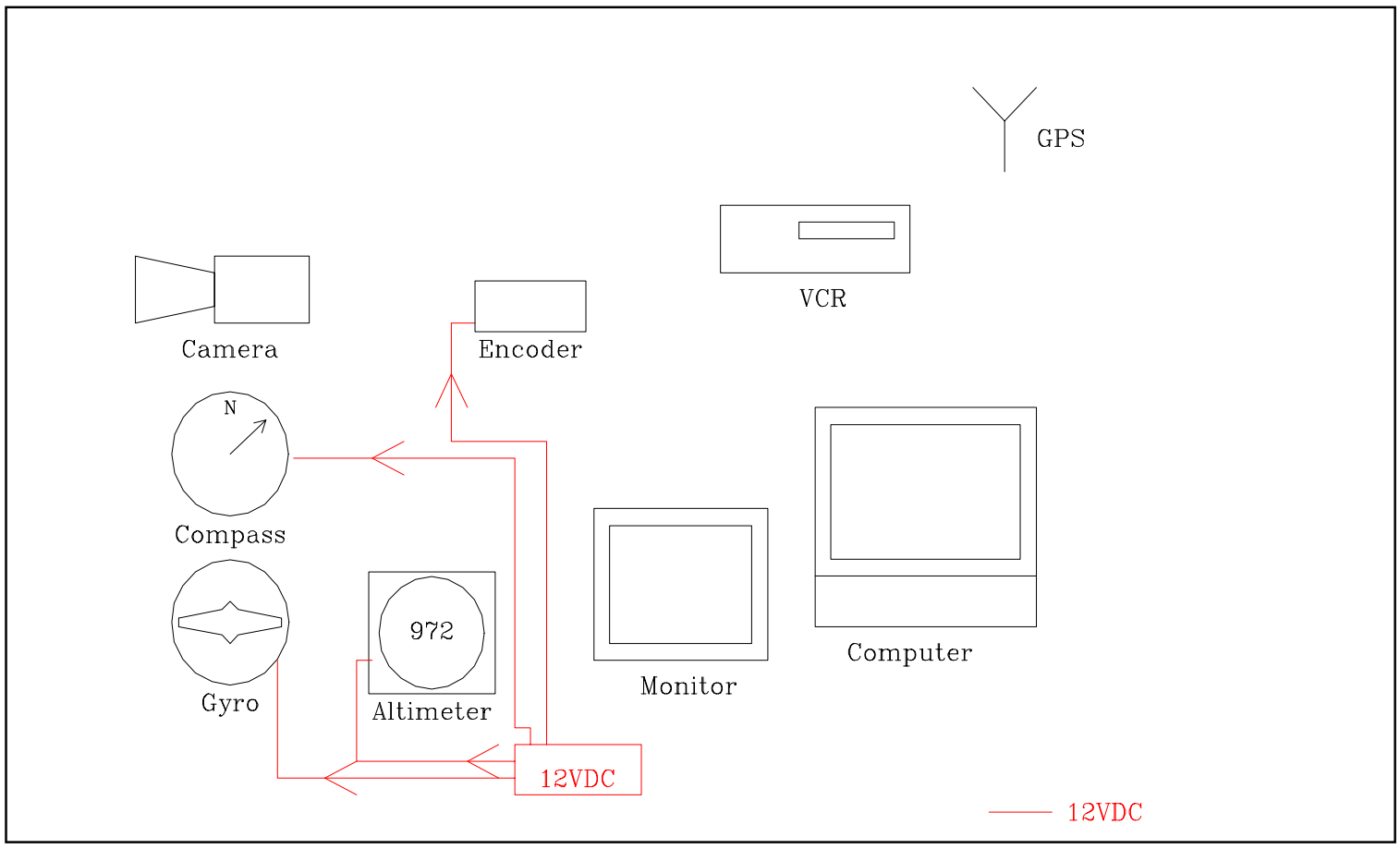

Figure 4. 12-V d-c connections

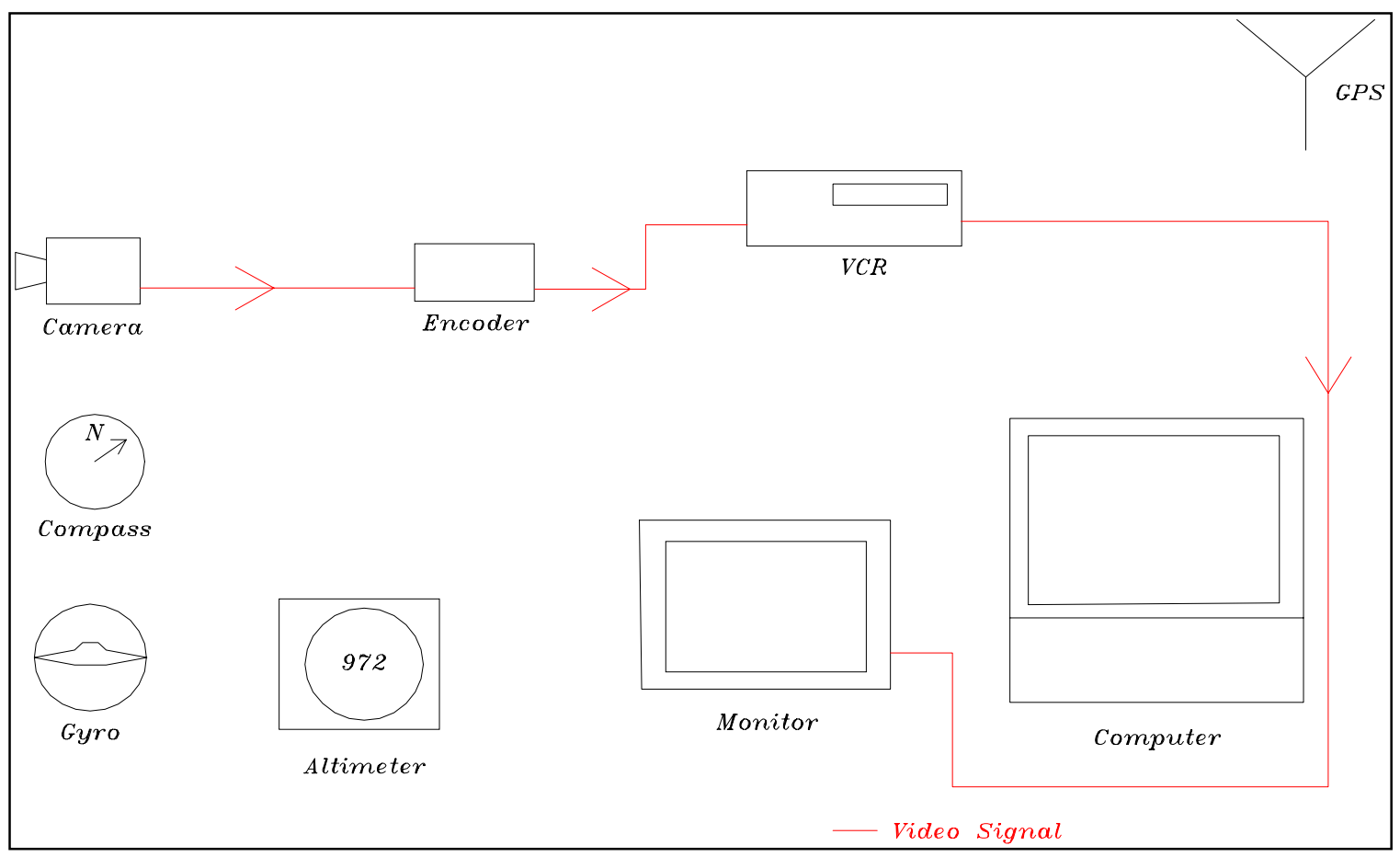

Figure 5. Video connections 
d. Step 4. Make the four sensor data connections shown in Figure 6. Connect cable from compass to Port A on the multiport board. Connect gyroscope to Port B, connect altimeter to Port C, then connect Port D on the multiport board to the COM port on the video encoder.

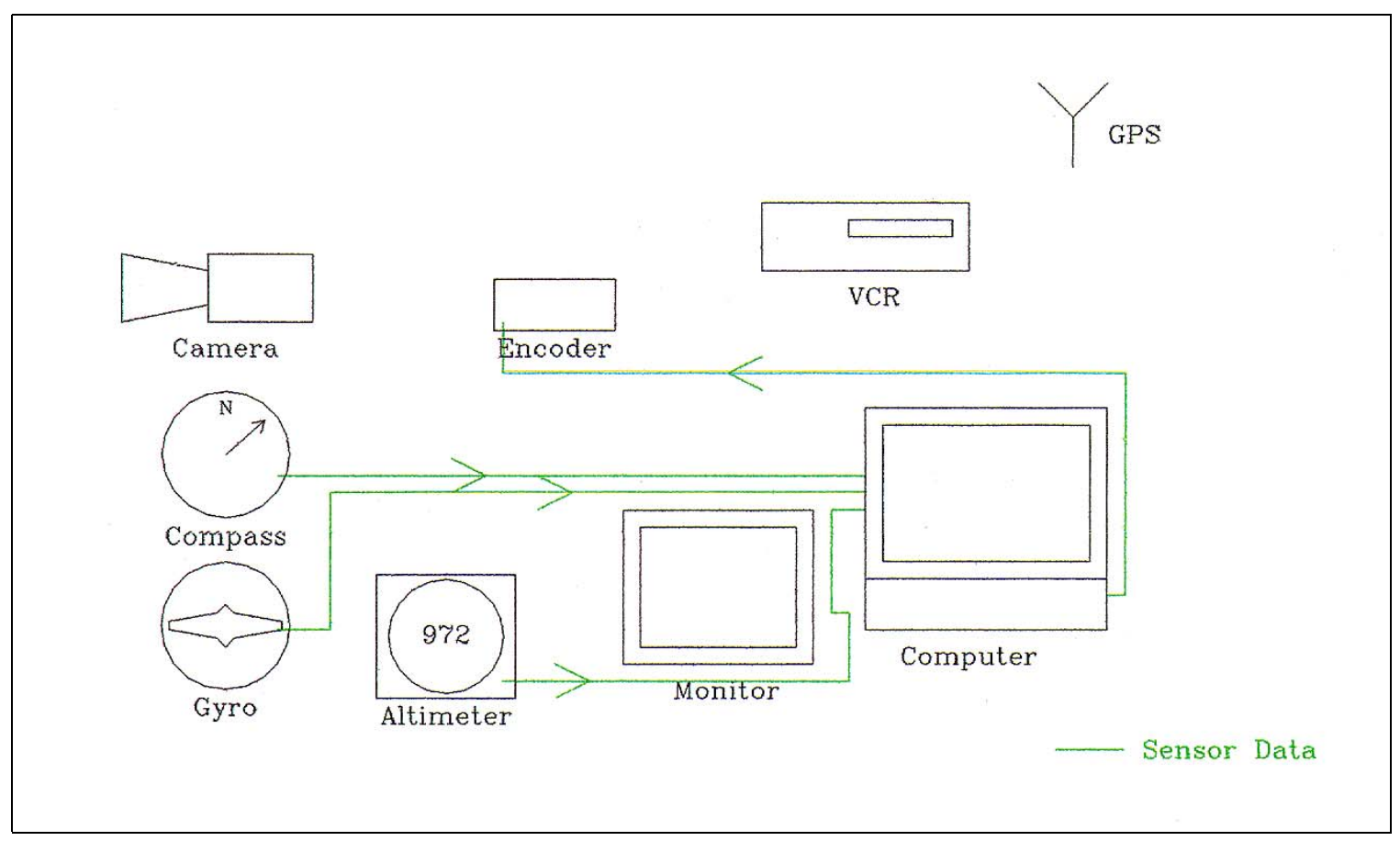

Figure 6. Sensor data connections

Hint: Adopt a standard connection methodology (i.e., always connect the sensor to the same port for each installation) to speed installation and to ensure proper operation of all the sensors.

e. Step 5. Make the two audio connections as shown in Figure 7. Connect the Time Code Out port of the video encoder to the audio input of the VCR. If adjustable, set audio record levels to maximum. Depending on the VCR and audio options available, it may be helpful to the analyst to record the comments of the field team. On the Panasonic AG-5700, the two audio channels can be kept separate. In this case, connect the audio output of the camera to the other audio input on the VCR. If the VCR used does not maintain two separate audio channels, but mixes them, then it would be best not to record any other audio than the time code. 

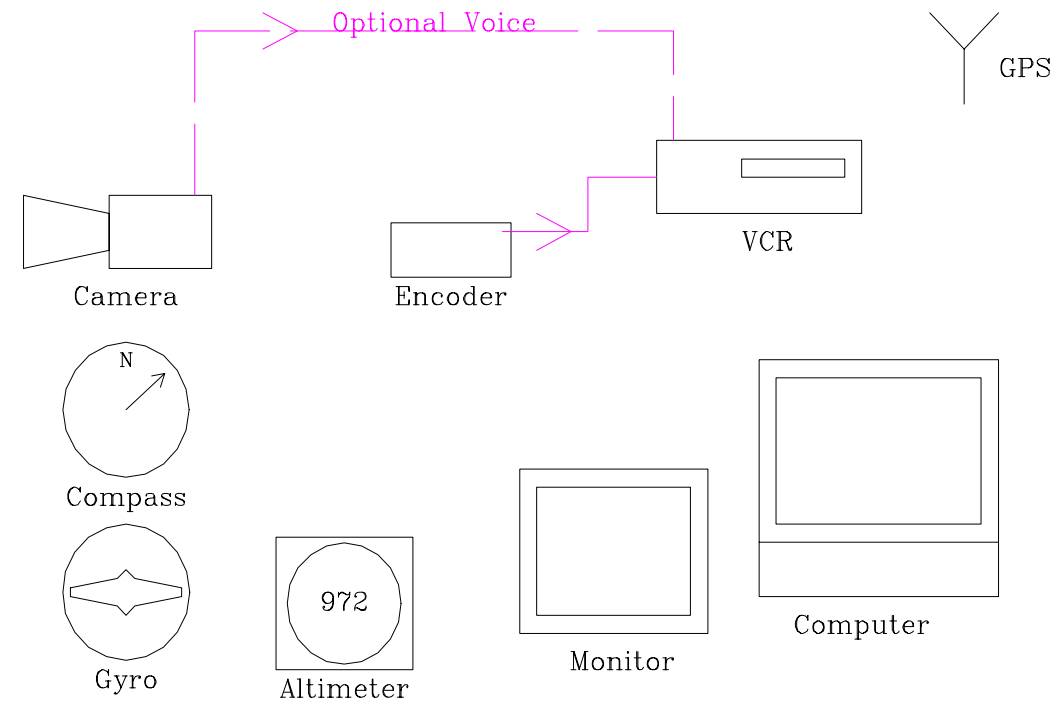

Computer

Monitor

Figure 7. Audio connections

Hint: If the VCR used does maintain separate audio channels, always connect the time code output to the same channel (either always right or always left). This will aid processing and eliminate guesswork by the analyst as to which audio channel has the time code signal.

f. Step 6. Install the GPS equipment. Place the antenna in a position for best sky visibility. In an aircraft, this may be on the dash. In a vehicle, the antenna may be placed on the roof using a magnetic mount. In a boat, the antenna may be secured to the boat rail or other high point using a mounting bracket. Next, connect a special three-connector cable to the output of the GPS. On the Trimble Pathfinder, there are two ports, one labeled RTCM In and the other labeled Data Out: connect to the Data Out port. The nine-pin connector of the three-connector cable should be connected to COM1 on the notebook computer. This provides the GPS signal for the mapping software. The third connector of the threeconnector cable is connected to the REM port on the video encoder. This provides the time and position information to the video encoder. These two connections are shown in Figure 8. 


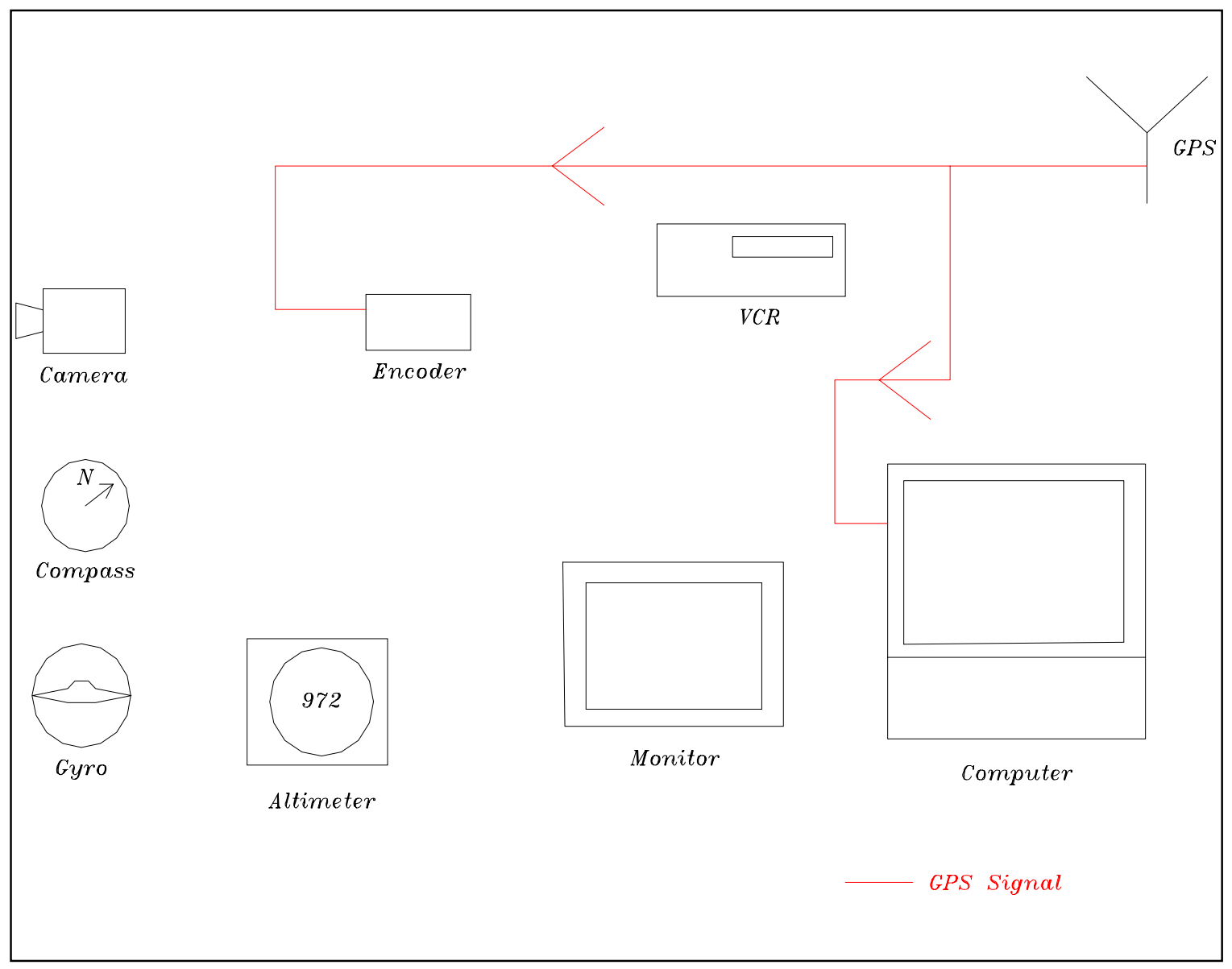

Figure 8. GPS connections

The order of Steps 1-6 is arbitrary. The object is to simplify the connections. The steps may be followed in any order; however, it is best to follow one signal from the source to final termination, before starting to connect another signal.

\section{Data Processing Software}

ArcView is a GIS software that allows users to visualize and analyze geospatial data on a personal desktop computer. The software is designed to allow additional analysis extensions to be written for additional functionality. The technical description of the IDAS extension for ArcView is given in Chapter 1.

The IDAS extension for ArcView adds the capability to:

a. Track the position of the data acquisition platform as played back from the recorded imagery.

$b$. Attribute selected positions with sensor attributes and captured image from the recorder. 


\section{IDAS Operations}

Basic operations of the IDAS are data acquisition and data processing and display. These are described in the following paragraphs.

\section{Data Acquisition}

Data acquisition operations involve two separate processes. The data acquisition mission must first be properly planned to collect the appropriate oblique imagery data at the proper scale/resolution. Then the actual data acquisition mission must be executed and analyzed. Data acquisition operations involve the basic video hardware and the data collection hardware as well as the data collection software.

\section{Mission planning}

Several issues must be addressed prior to the execution of an image acquisition mission. Among these are feature(s) to be imaged, type of imagery to be collected, and platform to be used. Other considerations include weather conditions and time of day.

Feature(s) to be imaged. Determining the features to be imaged is the most critical issue that must be addressed in mission planning. Concerns that need to be addressed include information about size of the feature, contrast between feature and the surrounding background, and the amount of detail required for the feature itself. Size of the features and the amount of detail required determine the field-of-view (FOV) settings for the mission. FOV determinations are also greatly affected by platform and look direction. Normal video (any RS-170 or SVHS imagery) consists of two interlaced fields. These fields are collected $1 / 60$ th of a second apart. In a fast-moving vehicle, imagery collected with a viewing geometry perpendicular to the line of travel will have the fields displaced due to the motion of the vehicle and the camera. In wide FOV imagery, this displacement is minimal because the pixel size of the imagery is as large as or larger than the amount of movement in the camera (an aircraft flying at 38.6 $\mathrm{m} / \mathrm{sec}$ ( 75 knots) will move $0.7 \mathrm{~m}(2 \mathrm{ft})$ in $1 / 60$ th of a second). In very narrow FOVs, this displacement can result in distorted imagery. Focus is another issue to be addressed. Many video cameras are equipped with automatic focus settings. When imaging from the air over water features (rivers or lakes), these cameras 
may lose focus when the primary feature (such as the shoreline or riverbank) is not in the FOV. The cameras are typically unable to focus on water, and it may take the camera a second or more to refocus on a riverbank or shoreline feature. Feature contrast may be more apparent in infrared (IR) imagery than in normal video imagery. Another issue is the purpose of the imagery to be collected (i.e., if the purpose is to count occurrences of a particular feature, a wider FOV is preferred; however, if the purpose is to obtain detailed information on the feature, then a narrower FOV, resulting in higher resolution imagery, would be required).

Type of imagery to be collected. The type of imagery to be collected determines the number of wave bands (visible, IR, etc.) and FOVs to be collected during an imaging mission. To some degree, the features to be imaged determine the type of imagery to be collected. Features such as seeps or boils (wet areas in and around levees) are much more detectable in IR imagery than in visible imagery. However, both types of imagery may be necessary to provide needed information on the feature. The need to collect multiple FOVs also determines the type of imagers to be used for the remote sensing mission.

Platform. IDAS may be deployed using aircraft, boats, or ground vehicles as the data acquisition platform. The choice of platform will be determined by required view geometry and the terrain in the area to be imaged. If a fairly flat terrain/feature viewing geometry is required, then either a boat or ground vehicle is used as the platform. If the required viewing geometry is more downlooking ( $>5 \mathrm{deg}$ from horizontal), then an aircraft platform is used. Altitude, airspeed, and standoff distance are determined from the viewing geometry requirements and the type of imagery to be collected. An altitude of $152 \mathrm{~m}(500 \mathrm{ft})$ and a standoff distance of approximately $305 \mathrm{~m}(1000 \mathrm{ft})$ provide a downlook angle of approximately $20 \mathrm{deg}$. Vehicle speed affects viewing geometry when imaging perpendicular to the vehicle path. Narrow FOVs become more prone to smearing and skewing as the vehicle speed increases. With an aircraft, the smearing and skewing may degrade the imagery if a very narrow FOV is required, depending on the minimum speed of the aircraft (helicopters can fly slower than fixed-wing aircraft). With ground vehicles, this is less a problem; however, platform vibration can also degrade the quality of the imagery. Some vibration may be reduced or eliminated by padding the cameras.

Other considerations. Time of day is important so that the terrain feature(s) may have the proper lighting (and temperature difference if using IR). Lighting also affects look or viewing (imaging) direction. When imaging over water, glare off the waterís surface may impact the quality of the imagery, particularly if the waterís surface is fairly smooth. Strong lighting sources, such as the sun, may cause flaring when the camera is looking in the direction of the source of the light.

Equipment selection. For most missions, data acquisition hardware will include the basic video hardware (encoder, monitor, video recorder) and the data collection hardware (camera, sensors, GPS, field computer, and inverter). Some missions may require special consideration. Space limitations and power requirements may preclude or necessitate the use of certain equipment. Some examples of special considerations might include power requirements and power 
availability. In an aircraft with only $24-\mathrm{V}$ d-c power available, either a $24-\mathrm{V}$ d-c inverter may be required along with a $12-\mathrm{V} \mathrm{d}$-c power supply or batteries may need to be used. If an analyst is to accompany the mission, some provision may be necessary to allow the analyst to review the features or areas being imaged as data are being collected. If certain imaging equipment must be continuously monitored, then an additional monitor is used. Depending on the situation, additional personnel may even be required to assist the operator in monitoring the equipment.

\section{Installation in various platforms}

IDAS is somewhat straightforward to install in most platforms. Special considerations must be taken to properly secure the equipment while providing access to both the vehicle and the components. In most cases it is better to avoid imgaging through glass to avoid glare problems and reflections from the glass surface. Power requirements are also somewhat platform dependent.

Aircraft. Care must be taken when installing the equipment in aircraft. In most cases it will be necessary to remove a door from the aircraft and secure the camera tripod in the open doorway. It is important that the camera system be secured to prevent the tripod from toppling during takeoffs and landings. Side-toside accelerations are typically not encountered during aircraft operations. The tripod may be secured to the seat of the aircraft or bungee cords used to secure the tripod to where the seatbelts are attached or to the frames of seats in the aircraft. Sudden accelerations can be generated upon takeoff and landing; therefore, the equipment must be properly secured to the platform. The video recorders and computer may be placed and secured on a seat. Depending on the cameras deployed, sufficient power may be available from the aircraft. However, aircraft systems may be either $12-\mathrm{V}$ $\mathrm{d}-\mathrm{c}$ or $24-\mathrm{V}$ d-c, so the proper selection of an inverter is required. For large power requirements, batteries may be necessary. Certain spillproof batteries are available and recommended. Headsets and an intercom are also desirable in an aircraft so that the camera operator may be in communication with the pilot as necessary. Figure 9 shows a two-video-camera IDAS installed in a Piper Lance aircraft.

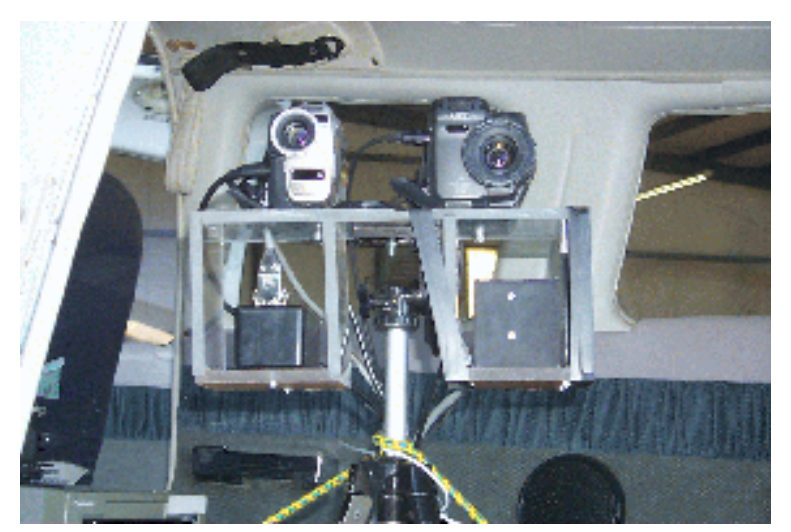

Figure 9. IDAS video equipment in an aircraft

Boats. In boats, protection of the equipment from moisture/water is the primary concern. The cameras and other sensors on the tripod are fairly safe as they are packaged in most conditions; however, rain or very heavy wave spray may require additional protection. The recorders, monitors, and computer may be 
housed in waterproof enclosures such as an ice chest. Batteries are generally necessary in a boat since most boats are not equipped with generators to provide extra power for the IDAS equipment. These should be the deep-cycle recreational vehicle type batteries for best performance. On larger boats with larger motors or inboard engines, sufficient power is usually available from the boat itself. Due to very flat vertical angles encountered in a boat platform, it may be necessary to add a laser rangefinder to the system to acquire a range to the feature instead of relying on the passive ranging approach used in the data processing software.

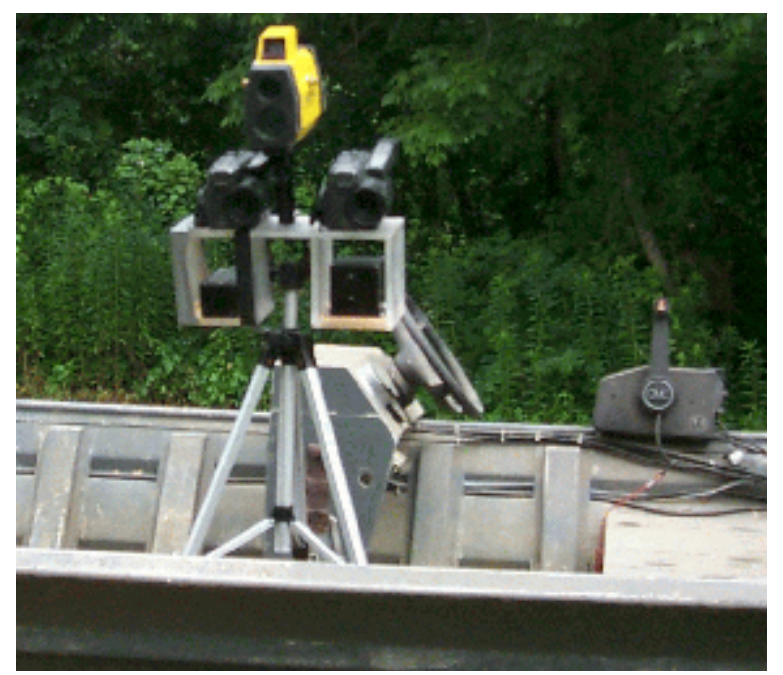

Figure 10. Sample installation in a boat Figure 10 shows an IDAS installation in a boat.

Ground vehicles. In ground vehicles, the camera tripod must be carefully secured front and back and side to side as it may be subject to lateral as well as front-to-back accelerations. Again it may be necessary to attach a laser rangefinder to the camera setup to measure the range to the feature. The recorders and computer may be placed in a position that is accessible to the operator. In most cases sufficient power should be available from the vehicle electrical system to preclude the use of extra batteries. Inverters are available that can plug directly into the vehicle cigarette lighter or power port. If more power is required, a larger inverter may be installed directly to the vehicle battery. If the operator is also the driver, special care should be exercised by the operator to ensure safe operation of the vehicle. Figure 11 shows an IDAS installation in a ground vehicle. IDAS may also be mounted with a forward-looking geometry (cameras imaging through the front windshield of the vehicle). Some glare or reflections may be visible in the imagery The dashboard of the vehicle should be cleared of any items that might reflect off the windshield. Always have a clean windshield.

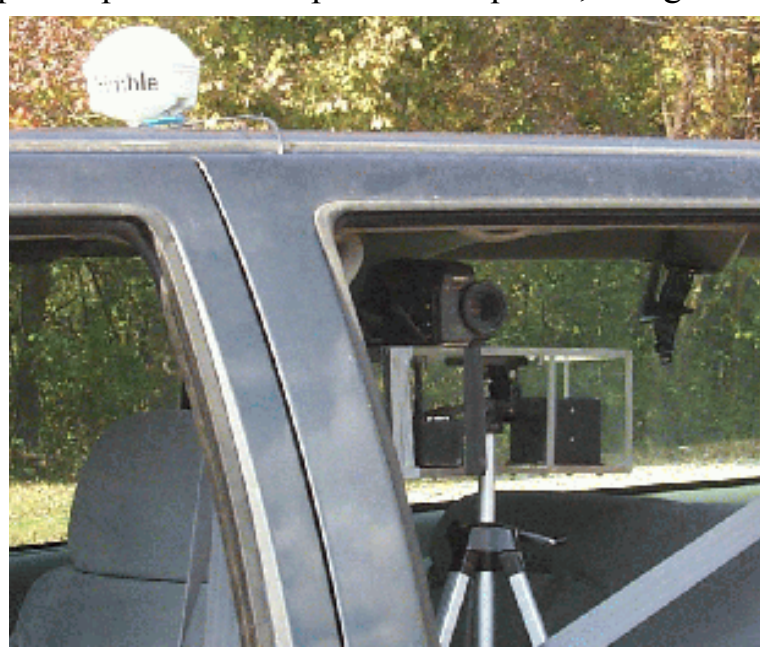

Figure 11. Sample installation in a ground vehicle 


\section{Hardware setup}

The hardware used for data acquisition comprises the hardware attached to the camera (which moves with the camera) and the hardware statically located (mounted in place in the vehicle, separate from the tripod and camera). The hardware associated with the camera includes the camera(s), compass, gyroscope, and optionally a laser rangefinder (to determine feature range for flat viewing geometries). The static hardware includes the video encoder, altimeter, VCR, monitor, computer, and GPS receiver. Equipment should be connected according to the instructions and diagrams in Chapter 2, "Wiring connections."

Note: LCD monitors tend to respond much more slowly than CRT monitors. This means that imagery when viewed using an LCD monitor will appear less sharp than when viewed on a CRT monitor. Similarly, imagery viewed using a multimedia interface on a notebook computer will appear much less sharp than when viewed on a CRT. Special care must be taken when using $L C D$ monitors or notebook computers to monitor the live imagery since focus and FOV problems may be masked by the slow response of the monitor.

\section{IDAS Data Acquisition Program configuration and operation}

The IDAS Data Acquisition Program is used to integrate the data from the compass, gyroscope, and altimeter and format it for recording by the video encoder (Horita GPS-3). The application is initiated by double-clicking the IDASDataAc icon on the desktop. Once the application has started, it is necessary to configure the application to communicate with the sensors (Figure 12). Once a sensor is selected, the Serial Port Selection menu (Figure 1) is displayed. Select the port to which the sensor is connected. The other communication parameters have been configured in the application and need not be changed by the user. Once a serial port has been assigned to a sensor, it will be "greyed out" in the port selection menu and cannot be reselected. The SAVE option has not been implemented in this release, but in the next release, it will allow the user to store a particular configuration and reload it. Also no option has been included in this release to reset the serial port selections. All sensors need not be configured for the application to operate. Missing sensor values will be replaced with zeros during operation.

Hint: Developing a standard connection scheme for the sensors will simplify installation and configuration.

Once all the sensors have been configured, it is necessary to calibrate the compass for the static magnetic field of the platform vehicle. Compass calibration is initiated from the FILES menu. Once CALIBRATE COMPASS has been selected, the user will be queried to confirm that action (Figure 13). To calibrate the compass, it is necessary to rotate and tilt the compass module (tripod head) one complete revolution in approximately 1 minute. Compass calibration is recommended for each installation to allow the compass to measure the magnetic field in the platform (with other sensors and electronics operating) and cancel out those effects during operation. The second edit box to the right of AZIMUTH 


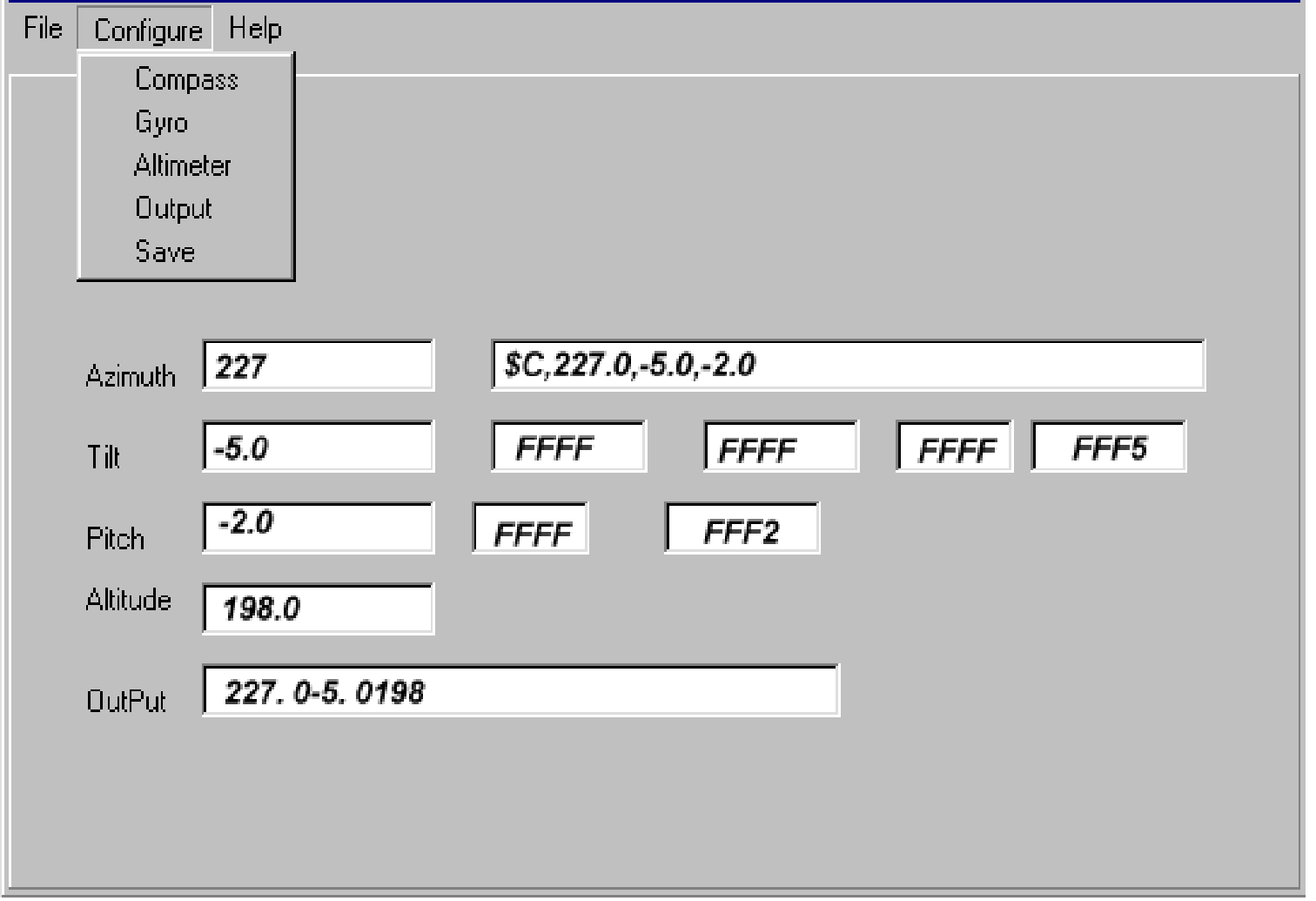

Figure 12. Data collector configuration menu

will display the output string from the compass while it is being calibrated. After 1 minute, the application will display a ì calibration scoreî in the form $\mathrm{HnVnMn}$. The HnVn describes the quality of the calibration in the horizontal and vertical components, respectively. An example of a good score would be H9V9 while that of a poor score would be H5V2. If a poor score is returned, then it is necessary to recalibrate the compass. Possible causes for poor scores are listed in Chapter 5. The Mn.nn numbers relate to the strength of the magnetic field in the local environment.

After the compass has been calibrated, selecting START from the FILES menu will initiate sensor sampling and output to the GPS-3. To suspend sampling, select STOP from the FILES menu. To exit the application, select EXIT from the FILES menu.

\section{Mapping application configuration}

The mapping program is used to monitor the platform location while collecting imagery. It may contain the location of specific features to be monitored and provide the camera operator prior notice that important features are approaching so that he or she can ensure that imagery on those features is collected. Many suitable mapping programs are available, and most will use data strings 


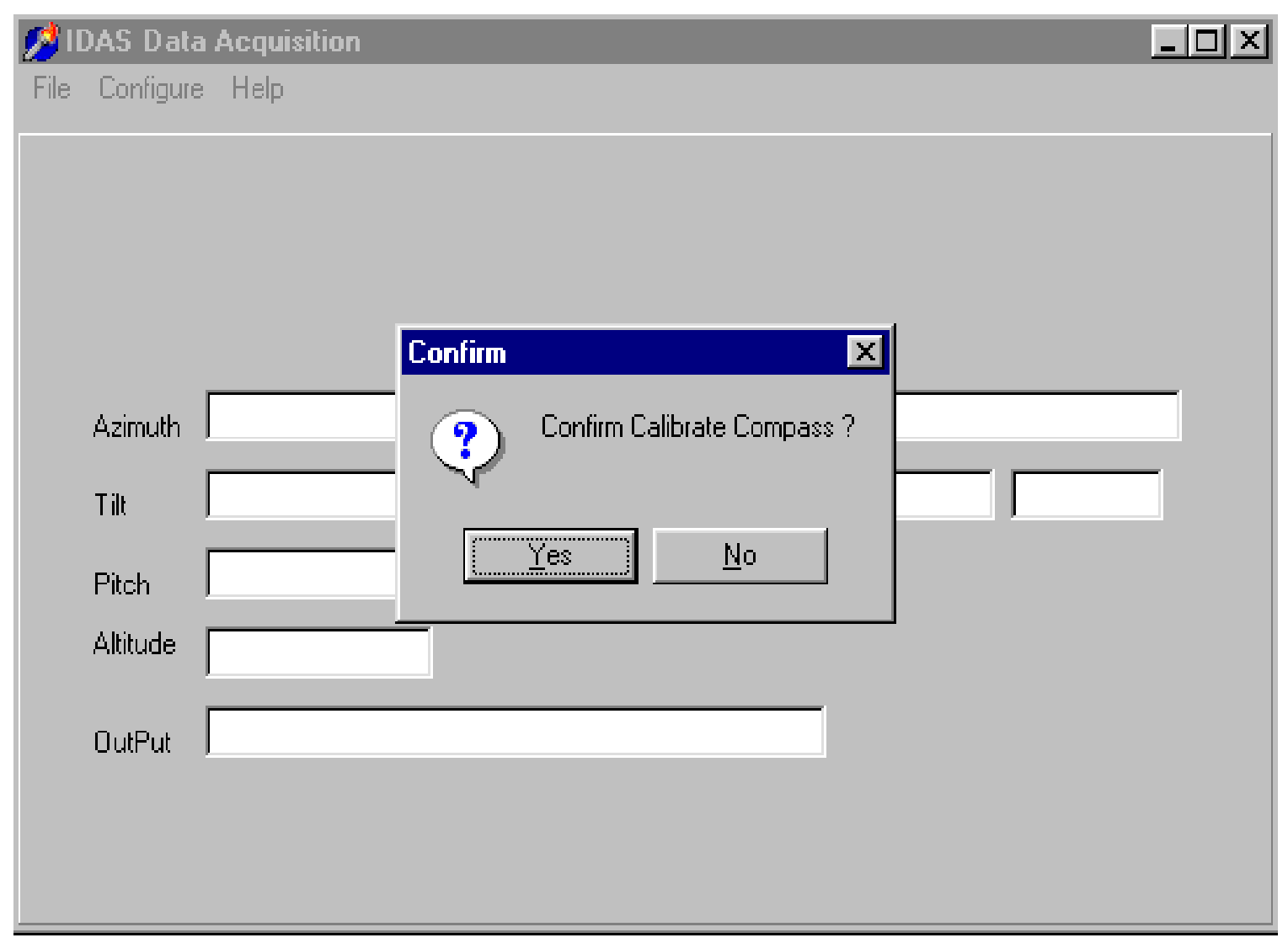

Figure 13. Compass calibration confirmation

described in the NMEA 183 specification. Delorme Street Atlas has been used with IDAS as a mapping application; however, other packages such as Delorme Topo USA, Georesearchís Geo-Link, and ESRIís Tracking Analyst all use the NMEA 183 data and could be used. Each application should be configured according to the manufacturerís instructions.

Note: Many of the commercial mapping packages such as Streets are not able to receive data on serial ports other than the standard ports (COM1-

COM4). It is advisable to connect the sensors to the extended ports available on the multiport board and reserve the built-in port (COM1) for the mapping application.

\section{Data Processing and Display}

\section{Data processing wiring diagram}

For data/image processing, the basic video hardware should be connected as shown in Figure 14. Connect the Video Out from the recorder to the Video In of the encoder/decoder, then connect the Video Out of the encoder/decoder to the Video Port on the computer. Optionally, a monitor may also be added to view the 


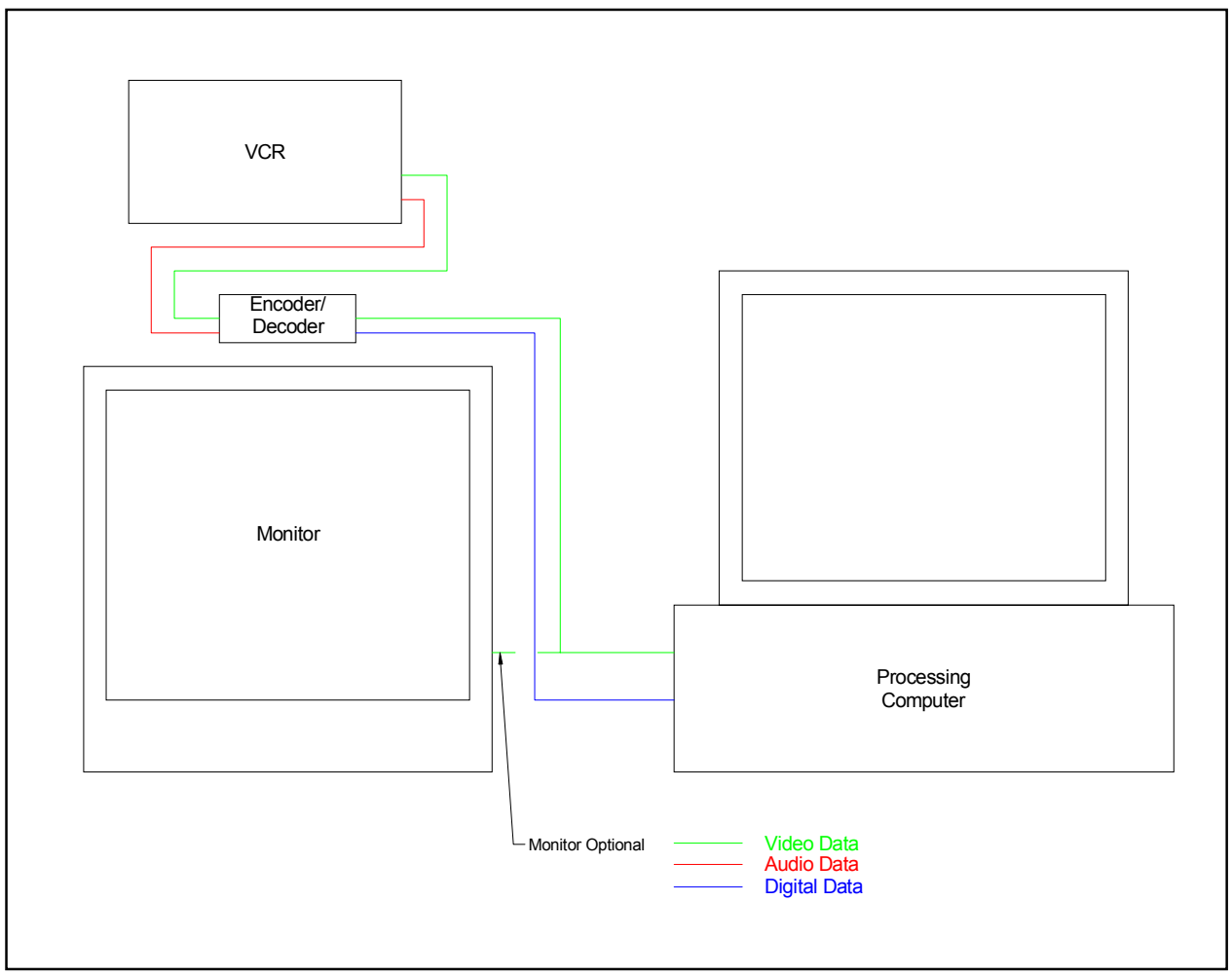

Figure 14. Data processing schematic

imagery. Connect the Audio Out from the recorder to the Time Code In on the encoder/decoder (if dual-channel audio has been used, be sure to connect to the proper audio output on the VCR, left or right channel). Connect the COM port on the encoder/decoder to the COM1 port on the processing computer. The system is now ready for data processing.

\section{Data processing application instructions}

After the IDAS ArcView Extension software is loaded into ArcView, open a new or an existing view within ArcView that will encompass the travel area of the measurement vehicle. Do the following steps:

a. Step 1. Make sure that the VCR player and video encoder/decoder are correctly connected to your computer.

b. Step 2. Start up the IDAS display software (idas_decode.exe).

c. Step 3. Begin playing the recorded video on the VCR.

d. Step 4. The video image should be displayed in the upper window of the IDAS display software. If not, make sure the VCR is correctly connected and then check which video feed the software is using by clicking the button labeled VIDEO SOURCE (Figure 15). 


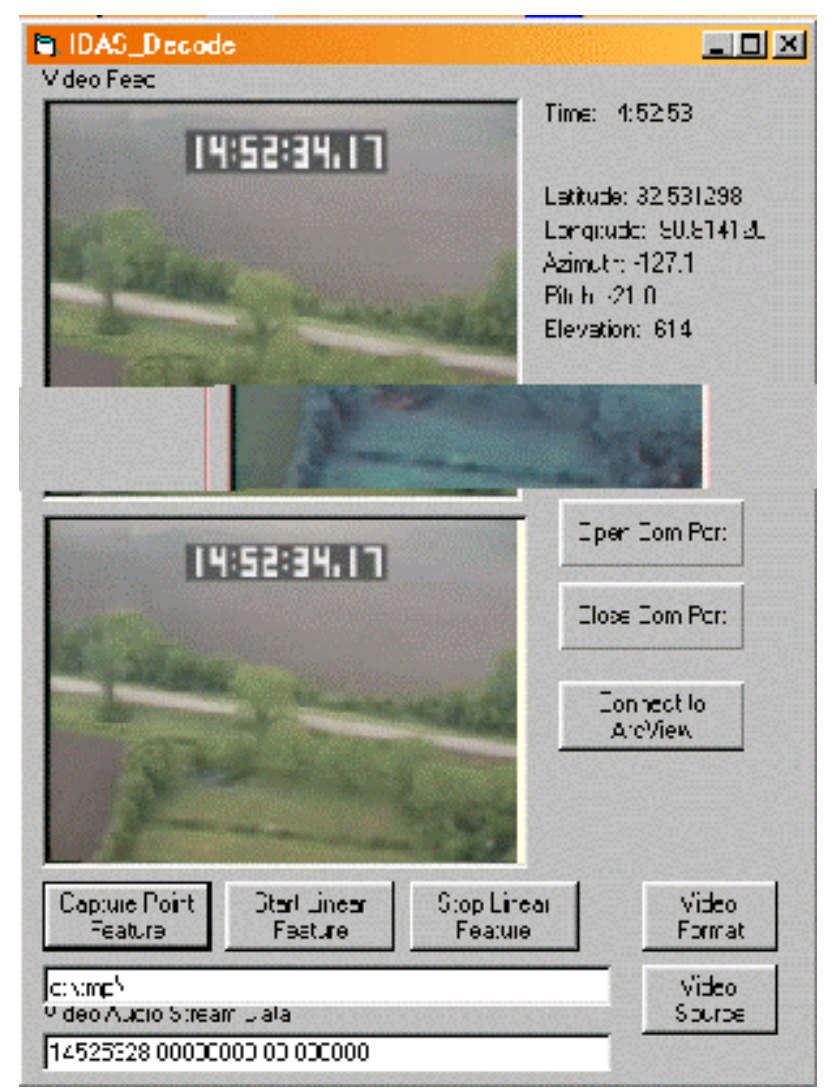

Figure 15. IDAS data processor display application

e. Step 5. Make sure the encoder/decoder is powered on and the RDR/GEN switch is set to RDR and correctly connected to the COM1 port of your computer.

f. Step 6. Click the button labeled OPEN COM PORT to begin processing the data stream from the encoder/decoder. If this is correctly working, next to the top display window, you will see a time code and positional attributes displayed and updated every second. The video-audio data stream will also be displayed in the bottom text box of the program.

g. Step 7. In the second to bottom text box, enter the directory name where captured video frames will be stored. The default for this is c: $\mid \mathbf{t m p} \backslash$. It would be appropriate to store the captured frames in a directory structure within your project area such as d:Imiss_river|april29.

h. Step 8. In ArcView, open a new or an existing view that will encompass the travel area of the platform (vehicle, boat, aircraft).

i. Step 9. In the VIEW menu bar there will be a pulldown menu labeled IDAS INTERFACE. Under this pulldown menu there is an item labeled IDAS START UP, select this item to begin the interface connection with the IDAS display program (Figure 16). 


\section{ArcView GIS Version 3.1}

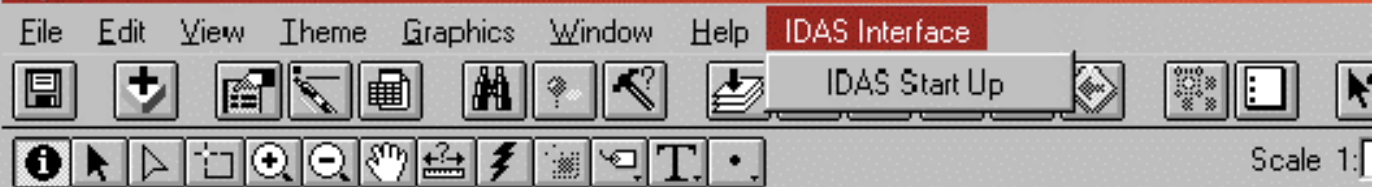

Figure 16. Menu for ArcView IDAS start up

(1) Selecting this item will display a prompt (Figure 17). This prompt determines if data will be appended to an existing data point file (Point Theme in ArcView terminology) or if a new data file will be created.

(2) If you choose to append to an existing point theme, ArcView will list all available point themes in the current view and the one chosen will be used in the data collection.

(3) If you choose not to append to an existing point theme, ArcView will prompt for a new name of a point theme to be generated. After this, all data will be added to this point theme.

\section{A Append to existing theme?}

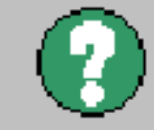

Do you want to apperid to an existing theme?
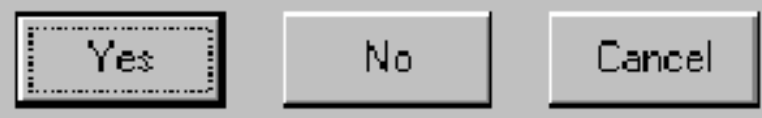

Figure 17. Prompt to append to or create new point data file

j. Step 10. At this point all the components of the IDAS data processing software are ready for communication with one another. Select the button on the IDAS display program labeled CONNECT TO ARCVIEW (Figure 15). At this point a small moving blue dot will appear on the ArcView view window indicating the position of the measurement vehicle.

k. Step 11. To begin processing points of interest, press the button labeled CAPTURE POINT FEATURE on the IDAS display program. This action will grab a frame of the video, save it to the specified directory indicated in Step 7, pass all the attribute information to ArcView, and add the data point to the point theme selected in Step 9. The selected point will appear on the view as two points, one the position of the measurement vehicle and the second the calculated center position of the captured video frame. 
l. Step 12. Repeat this process as required. To stop data feed to ArcView, simply close the COM1 port on the IDAS display software by pressing the CLOSE COM PORT button. 


\section{Example IDAS Mission}

\section{Mission Objective}

The objective of this example remote sensing mission was to document structures in a portion of the Yazoo River Basin of the Mississippi Delta region (area enclosed in blue line in Figure 18) north of Vicksburg, MS (Table 1). Information was required about structure type and usage in the areas along the major roadways in the region as well as pier density along the shore of Eagle Lake. Imagery was to be of sufficient detail to determine structure type and use. Imagery was also collected on the Sunflower River banks and control structures and at Steele Bayou. Imagery of Mississippi River banks was also to be collected.

\begin{tabular}{|c|c|}
\hline \multicolumn{2}{|c|}{$\begin{array}{l}\text { Table } 1 \\
\text { Example IDAS Mission }\end{array}$} \\
\hline Features imaged & $\begin{array}{l}\text { Structures along major roads for structure type and usage } \\
\text { Pier structures on Eagle Lake for waterfront density. } \\
\text { determinations (permitting application). } \\
\text { Shoreline conditions along Mississippi and Sunflower Rivers for } \\
\text { erosion documentation and control efforts. } \\
\text { Structures on Sunflower River and Yazoo Diversion Canal (Steele } \\
\text { Bayou) for general terrain conditions and water level differences. } \\
\text { Erosion control structures along Mississippi River. }\end{array}$ \\
\hline Type of Imagery collected & Medium FOV video imagery \\
\hline Platform & Fixed-wing aircraft \\
\hline Flight Parameters & $\begin{array}{l}\text { Airspeed: } 75 \text { knots }(38.5 \mathrm{~m} / \mathrm{sec}) \\
\text { Altitude: Two passes at two altitudes, } 500 \mathrm{ft} \text { Above Ground Level } \\
\text { (AGL) and } 1,000 \mathrm{ft}(304 \mathrm{~m}) \mathrm{AGL}\end{array}$ \\
\hline Distance to features & Approximately 1,500 to $2,000 \mathrm{ft}(457$ to $610 \mathrm{~m})$ \\
\hline Time of Day & $\begin{array}{l}\text { Midmorning, approximately 10:00 AM (1500 Greenwich Mean } \\
\text { Time (GMT)) }\end{array}$ \\
\hline Mission Planning & $\begin{array}{l}\text { Size of Features: Most structures are fairly large in size. Resolution } \\
\text { should be sufficient to determine number, type, and usage of } \\
\text { structures. Erosion features are smaller in size and resolution } \\
\text { should be increased (zoom in) during these portions of the mission. } \\
\text { Erosion control structures are larger; however, more detail is } \\
\text { required to determine effectiveness of structure. }\end{array}$ \\
\hline Weather Conditions & Overcast sky, ceiling approximately $5,000 \mathrm{ft}(1,524 \mathrm{~m})$ \\
\hline Equipment & Standard IDAS equipment with one camera \\
\hline
\end{tabular}




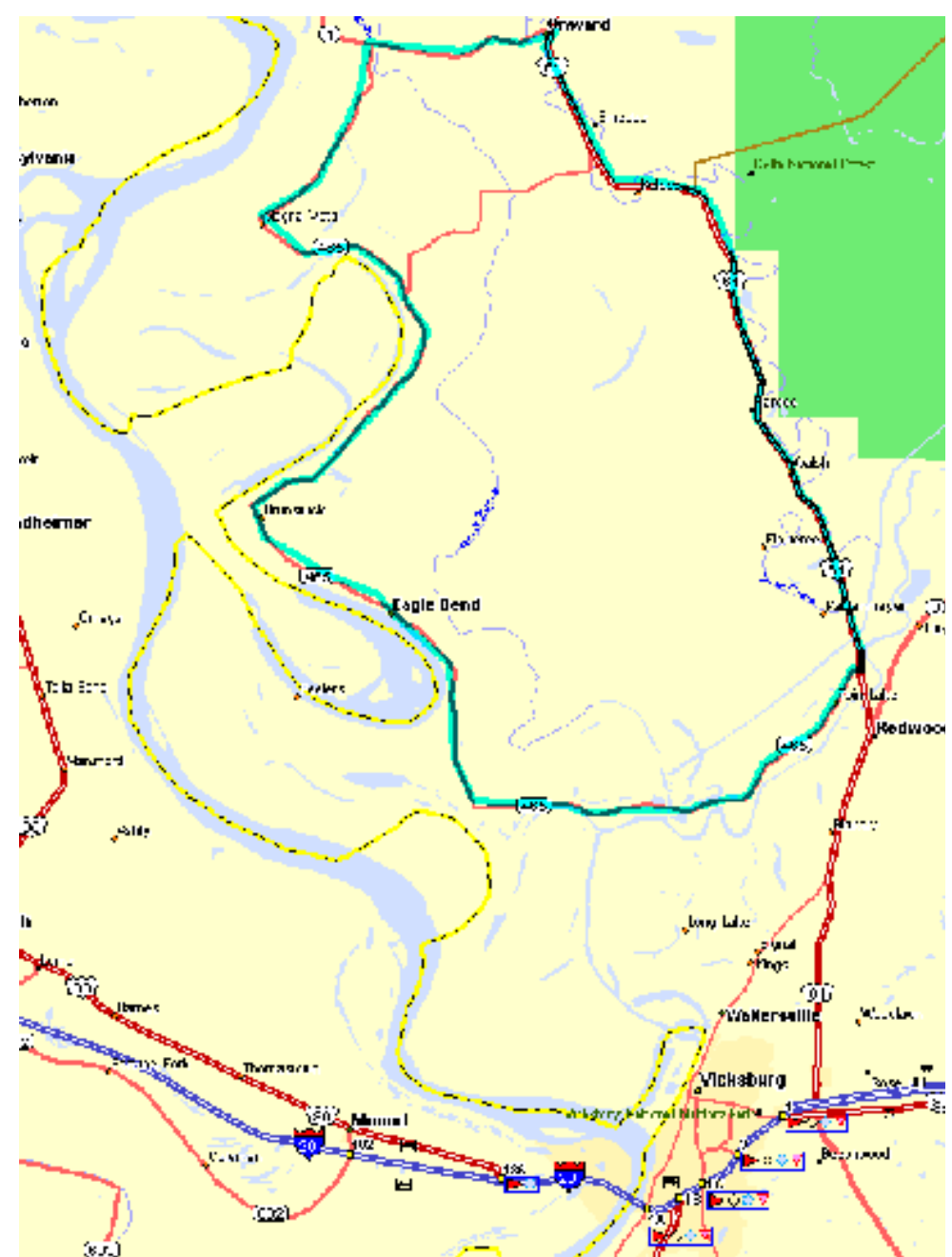

Figure 18. Data acquisition area

\section{Imagery Data Acquisition Mission}

The mission was executed on 29 April 1999 and started from Vicksburg Municipal Airport. Personnel on board included the pilot, an observer, and a camera operator. The IDAS equipment was installed in the aircraft, which took approximately 45 minutes (Figure 19). The aircraft used for this mission was a Piper Lance. The rear door on the left side of the aircraft was removed and the camera tripod was secured in the door (Figure 20). A bungee cord was looped around the neck of the tripod and secured to seat attachment points on the floor of the aircraft. Upon reaching the data acquisition area, the aircraft descended to approximately $500 \mathrm{ft}$ AGL, slowed to approximately $75 \mathrm{knots}(38.5 \mathrm{~m} / \mathrm{sec})$, and proceeded to circle the primary data collection area. Once imagery had been collected along the primary mission area, the aircraft proceeded up the Sunflower River to the control structure. After circling the control structure, the aircraft proceeded down the Sunflower and over to the structure at Steele Bayou. After circling that structure, the aircraft flew to 
Eagle Lake, entering from the northern end of the lake. It first circled at $500 \mathrm{ft}(152 \mathrm{~m})$ AGL, then it climbed to $1,000 \mathrm{ft}$ (304 m) AGL for a second pass. From Eagle Lake the plane flew west to the Mississippi River, then downriver to Vicksburg. The total imaging time was approximately 90 minutes and the cost for the aircraft for this mission was approximately $\$ 500$. The actual path of the aircraft is shown in Figure 21. This map was generated using Delorme Map Expert using position data recorded on the imagery. Imagery was collected over several structures in the region. Most of the structures away from Eagle Lake were agricultural in nature, either barns, silos, and other traditional agricultural structures, or farm houses. A couple of small communities were

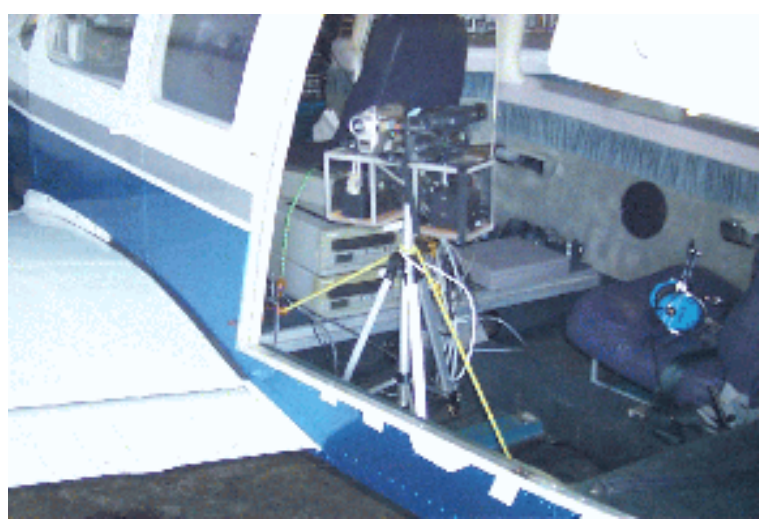

Figure 19. IDAS equipment in aircraft

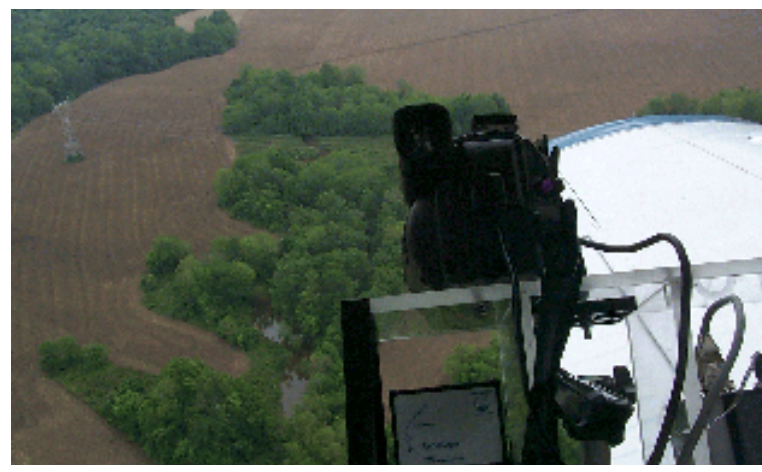

Figure 20. IDAS camera in door of aircraft overflown as well with more traditional residential and commercial structures. Table 2 shows examples of the features imaged. The time shown in these images is the GMT time the images were collected and the coordinates shown are those of the aircraft.

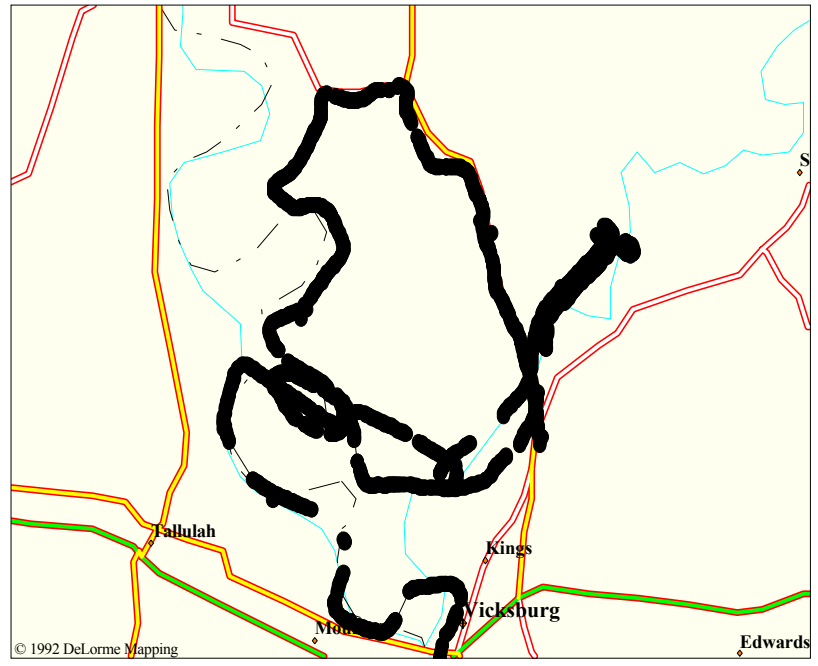

Figure 21. Mission route for 29 April 1999 


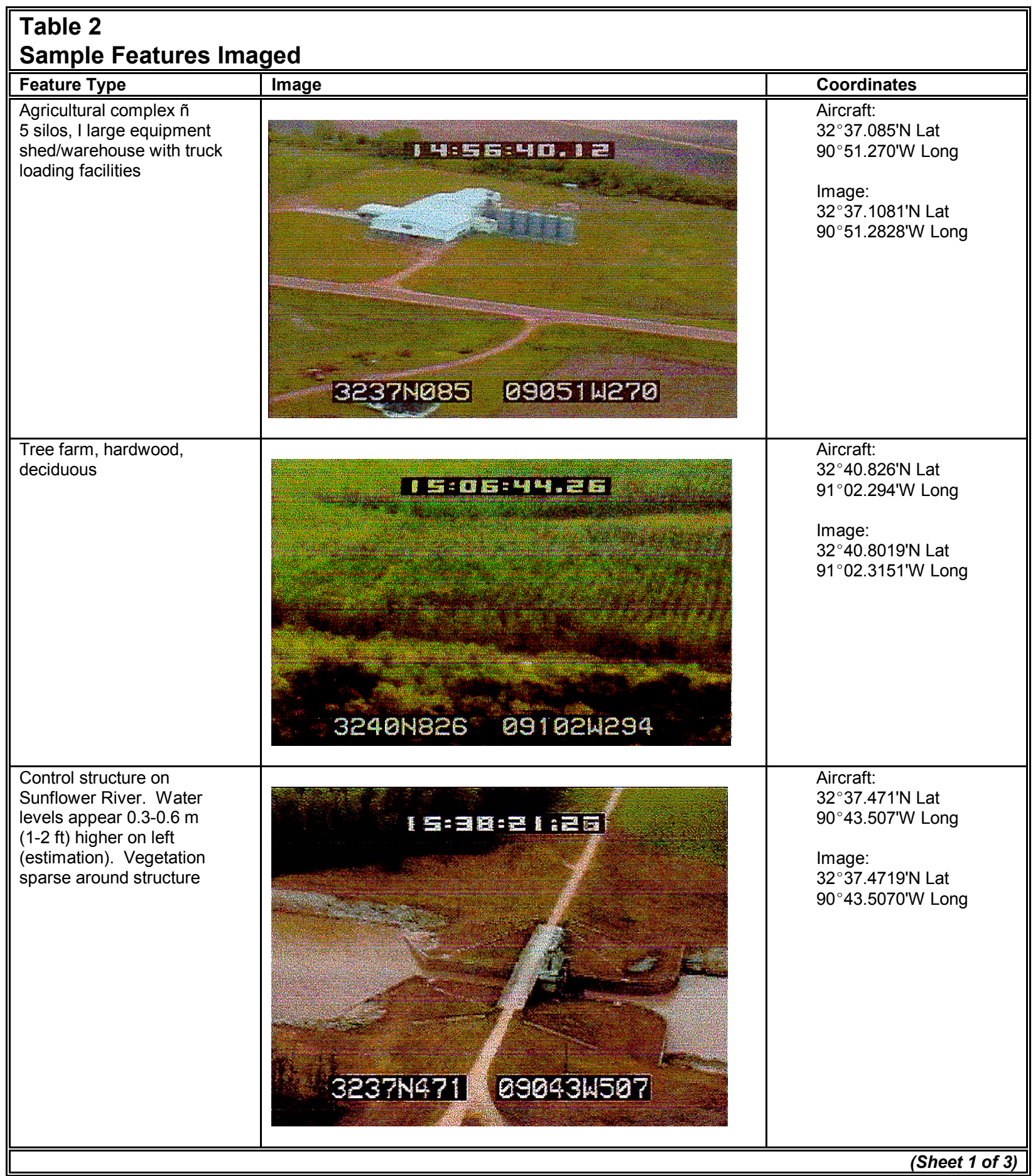




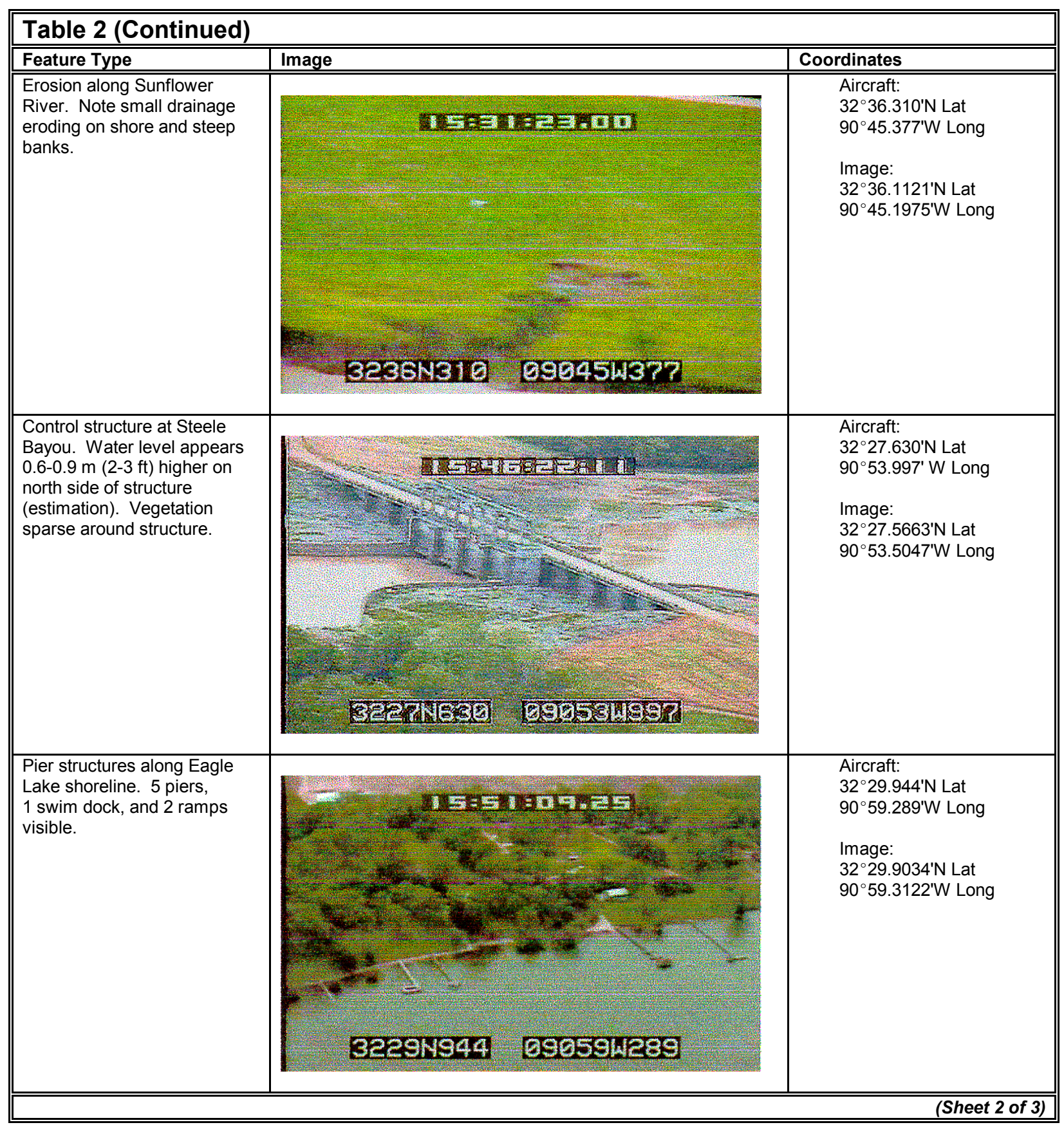




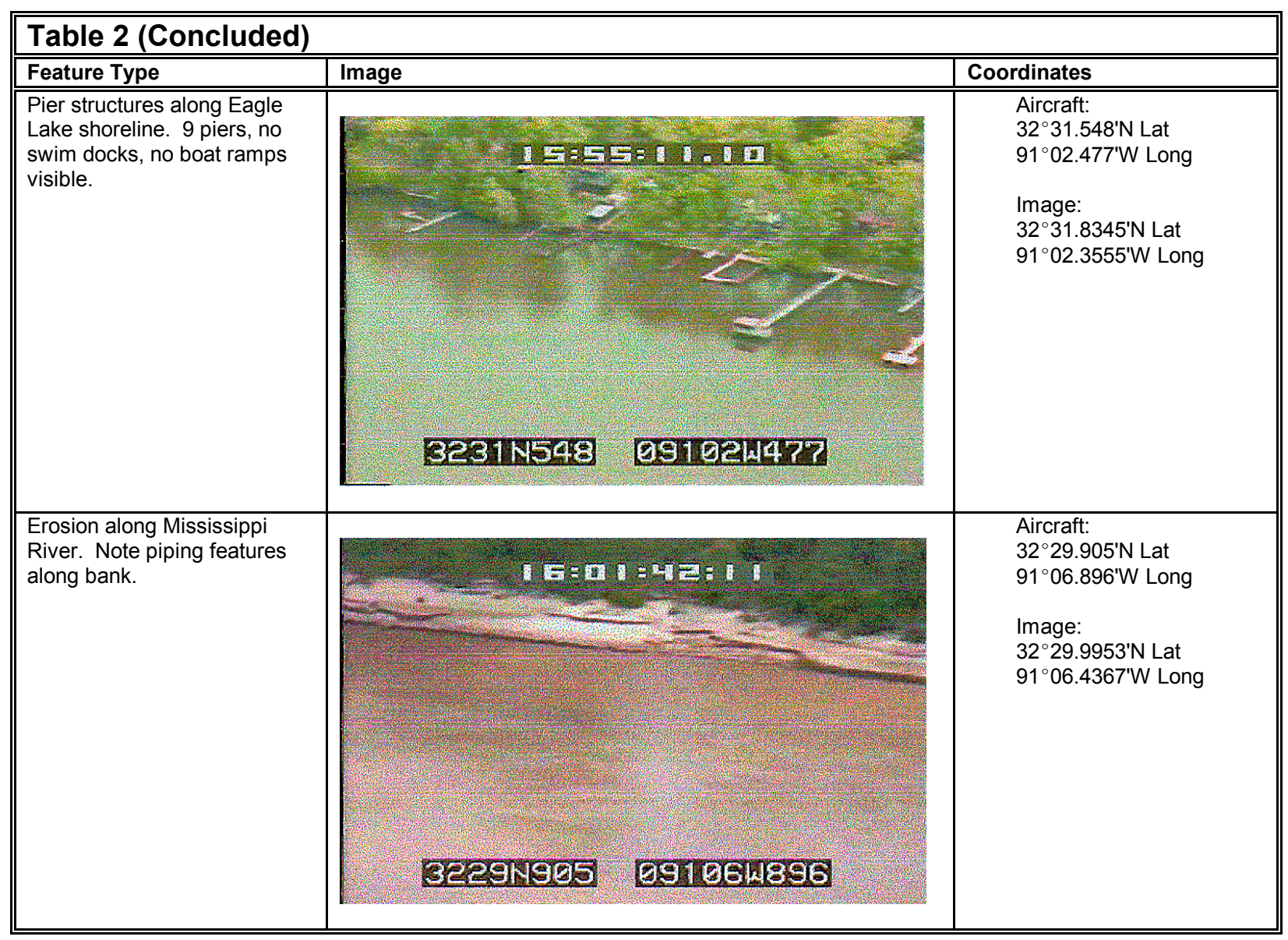

\section{Imagery Data Processing and Display}

The video tape from the mission was processed using the IDAS_decode application and ArcView GIS package. Eight features were selected and analyzed and coordinates were computed for each frame. A description of the features is presented in Table 2. The time shown at the top of the image is in Universal Time Coordinated (UTC) and the coordinates shown at the bottom of the image are those of the aircraft. 


\section{Troubleshooting}

Table 3 presents potential problems, causes, and solutions.

\begin{tabular}{|c|c|c|}
\hline \multicolumn{3}{|c|}{$\begin{array}{l}\text { Table } 3 \\
\text { Troubleshooting }\end{array}$} \\
\hline Problem & Possible Cause & Solution \\
\hline \multirow[t]{2}{*}{$\begin{array}{l}\text { No response from } \\
\text { sensors on startup }\end{array}$} & $\begin{array}{l}\text { Power supply not connected. } \\
\text { Blown fuse in power supply } \\
\text { No power available (aircraft } \\
\text { primarily) }\end{array}$ & $\begin{array}{l}\text { Connect power supply } \\
\text { Replace fuse/reset breaker } \\
\text { Switch on aircraft mains/power supply }\end{array}$ \\
\hline & $\begin{array}{l}\text { Loose connections } \\
\text { Improper configuration }\end{array}$ & $\begin{array}{l}\text { Check connections } \\
\text { Exit application and reconfigure }\end{array}$ \\
\hline \multirow[t]{2}{*}{$\begin{array}{l}\text { Sensors stop } \\
\text { responding }\end{array}$} & $\begin{array}{l}\text { Blown fuse/breaker } \\
\text { Power supply dislodged }\end{array}$ & $\begin{array}{l}\text { Replace fuse/reset breaker } \\
\text { Reconnect power supply } \\
\end{array}$ \\
\hline & $\begin{array}{l}\text { Loose connection on } \\
\text { sensor/multiport card }\end{array}$ & $\begin{array}{l}\text { Reseat connector then restart processor } \\
\text { (file/start) }\end{array}$ \\
\hline \multirow[t]{3}{*}{ Poor calibration score } & $\begin{array}{l}\text { Insufficient rotation } \\
\text { Rotation too fast }\end{array}$ & $\begin{array}{l}\text { Rotate compass } 2 \text { full turns } \\
\text { Rotate more slowly }\end{array}$ \\
\hline & Insufficient tilt & Tilt compass more during recalibration \\
\hline & & $\begin{array}{l}\text { Attempt to reduce necessary electronics } \\
\text { Remove any magnetic sources }\end{array}$ \\
\hline $\begin{array}{l}\text { No time code } \\
\text { displayed }\end{array}$ & GPS-3 not turned on & Turn on GPS-3 \\
\hline \multirow[t]{2}{*}{$\begin{array}{l}\text { Time Code } \\
\text { 00:00:00:00 }\end{array}$} & No GPS & $\begin{array}{l}\text { Check GPS power } \\
\text { Check GPS NMEA Output } \\
\text { Check port settings on GPS }(9600, N, 8,1)\end{array}$ \\
\hline & GPS-3 in Reader Configuration & Set GPS-3 to Generate Configuration \\
\hline \multirow[t]{5}{*}{ No video } & Camera not on & $\begin{array}{l}\text { Turn camera on } \\
\text { Check power to camera } \\
\text { Check camera setting (Camera not Play) }\end{array}$ \\
\hline & No power To GPS & Check power to GPS-3 \\
\hline & VCR not on & $\begin{array}{l}\text { Turn VCR on } \\
\text { Check power to VCR } \\
\text { VCR not in Play mode } \\
\text { Check VCR switch setting } \\
\end{array}$ \\
\hline & Monitor not on & $\begin{array}{l}\text { Turn monitor on } \\
\text { Check power to monitor } \\
\text { Check monitor switch setting }\end{array}$ \\
\hline & Poor cables & $\begin{array}{l}\text { Check cable connections } \\
\text { Replace cables as necessary }\end{array}$ \\
\hline \multirow[t]{3}{*}{ No audio } & $\begin{array}{l}\text { Cable connected to wrong } \\
\text { connector }\end{array}$ & $\begin{array}{l}\text { During Data Capture, cable should be } \\
\text { connected to Time Code Out Connector } \\
\text { During Data Capture, cable should be } \\
\text { connected to Audio/Time Code In on } \\
\text { VCR }\end{array}$ \\
\hline & Audio Gain set too low & $\begin{array}{l}\text { Increase Audio Gain to maximum if } \\
\text { possible }\end{array}$ \\
\hline & Bad cables/connections & $\begin{array}{l}\text { Check connections } \\
\text { Replace cables as necessary }\end{array}$ \\
\hline
\end{tabular}




\section{Appendix A Description of Data Acquisition Hardware}

This appendix describes the data acquisition hardware used in this implementation of IDAS. Other users may select other hardware; however, software modifications may be necessary for proper operation.

\section{Compass}

The compass used in this implementation is the Precision Navigation TCM-2 (Figure A1). It is available as a component board to be installed in a user- supplied enclosure. It uses a 10-pin MOLX connector (Figure A2). In this implementation it was mounted in a plastic 5-by 2.5 - by 25 -in. box. Pins 2 and $3(12-\mathrm{V}+$ and ground, respectively) supply power and are connected to a coaxial connector mounted on the box. Pin 4 is the receive data pin and is connected to Pin 3 on a standard DB-9 connector. Pin 5 is the transmit data pin and is connected to Pin 2 on the DB-9 connector. Pins 7 and 10 provide data ground and share a common connection on the board.

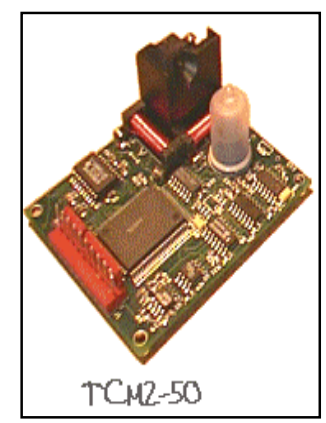

Figure A1. TCM-2 Module Pin 10 is brought out to Pin 5 on the DB-9. These are shown in Figure A3. The compass module is mounted flat with the main axis aligned with the center FOV axis of the camera. The compass module calculates the heading by measuring the three-dimensional magnetic field and rotating those measurements into the horizontal plane using data from the onboard fluid-filled tilt sensor. The compass then outputs the heading and roll and pitch data. The

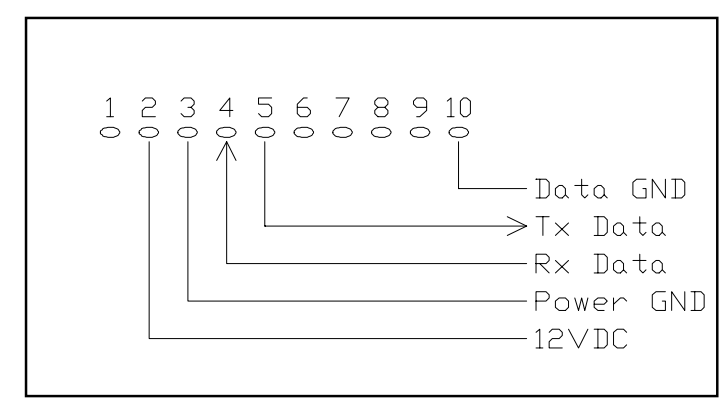

Figure A2. MOLX Connector One TCM-2 
compass has also been configured to output the magnetic data. The fluid-filled sensor is not reliable in dynamic situations where it may be subjected to lateral accelerations, so the data acquisition application uses the raw magnetic data along with roll and pitch information from the gyroscope to compute heading information. This sensor operates in a continuous mode once started. It transmits data at a $30-\mathrm{Hz}$ rate.

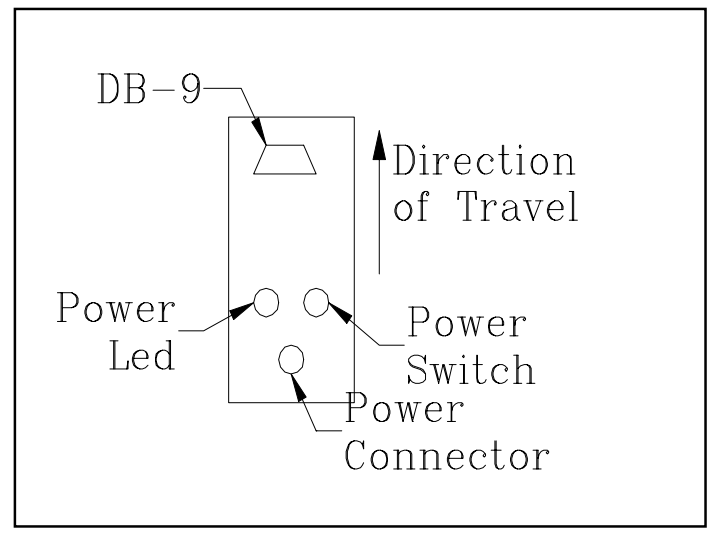

Figure A3. Compass box layout

\section{Gyroscope}

The gyroscope used in this implementation is the Cross-bow DMU-VG (Figure A4). This is a three-axis solid-state gyroscope. It comes ready to be mounted with a DB-15 connector. It is also mounted with the camera with the $\mathrm{X}$-axis of the gyroscope parallel to the center FOV axis of the camera. Data are transmitted from the DMU-VG on Pin 1 of the DB-15 and data are received by the DMU-VG on Pin 2. Pin 4 provides both data and power ground. 12-V d-c power is

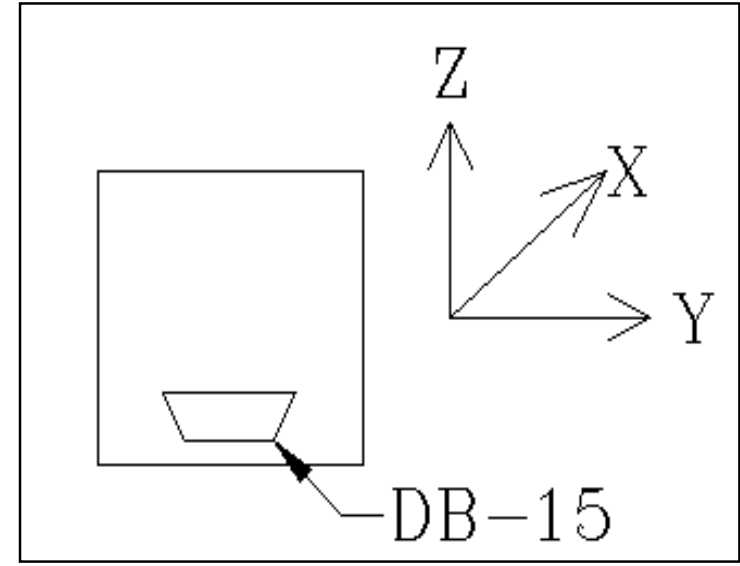

Figure A4. TCM-2 supplied on Pin 3 of the DB-15. The DMU-VG is operated in a polled mode, which means that the gyroscope provides roll and pitch data only upon request. The data collection program requests a new sample immediately after it has received and processed the prior sample. Tilt and roll data are combined with the magnetic data from the compass to calculate a camera look direction.

\section{Altimeter}

The altimeter used in this implementation is the Rocky Mountain Instrument Microencoder. The altimeter is mounted separately from the camera. Two connectors are present on the rear of the altimeter, a DB-9 female and a DB-15 female as well as two ports for vacuum lines (Figure A5). Data are transmitted from the altimeter on Pin 6 of the DB-9 and received on Pin 7. Pin 1 is used as both a data and power ground with $12-\mathrm{V}$ d-c being supplied on Pin 2 . A temperature sensor is connected between Pins 5 and 9, and the temperature data 
are used by the altimeter to calculate density altitude. This mode, however, is not used by the data acquisition application, and this sensor may be omitted without affecting the quality of the data. The DB-15 connector and the vacuum ports are not used. The altimeter operates in an automatic mode, outputting data at a $1-\mathrm{Hz}$ rate starting after power is applied and the

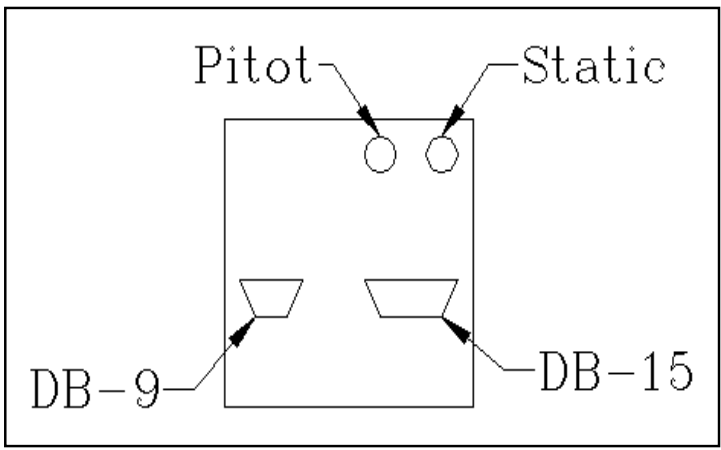

Figure A5. Microencoder layout altimeter completes its self-test.

The reference pressure setting may be adjusted to compensate for varying barometric pressure; however, in airborne applications, the pressure setting should be adjusted after takeoff. Since the altimeter is not connected to the aircraft pitot and static lines, the indicated altitude is affected by the airflow inside the aircraft. In operation, the pressure setting should be adjusted to match the aircraft altimeter after the plane has leveled off prior to the start of the data acquistion mission. The altitude should be checked and updated during long missions by information broadcast from area airports. This situation may or may not be encountered with other altimeters.

\section{Video Encoder}

The video encoder used in this implementation is the Horita GPS-3 (Figure A6). It uses the NMEA 183 GGA string to record position and time data on the video. Incoming video is connected to the Video In port. The GPS-3 first syncs its internal clock with the GPS then uses the video frame as a clock pulse generator. The time can

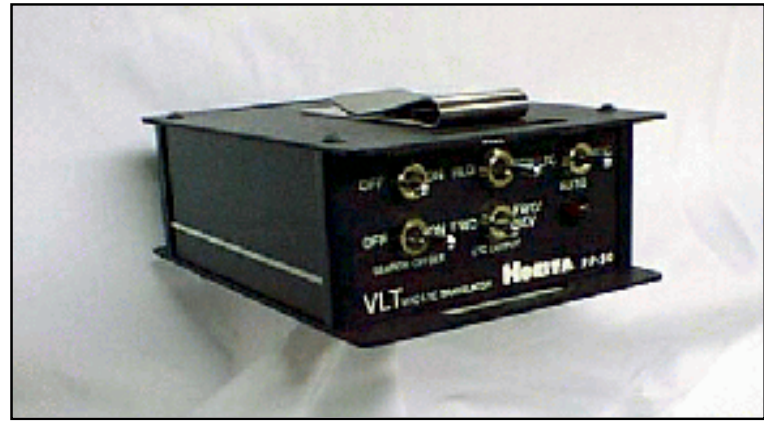

Figure A6. Horita GPS-3 be displayed at three locations on the video via a switch on the front panel. The GPS-3 may be connected either between the camera and the VCR (in which case a displayed time will be burned onto the recorded video) or between the VCR and the monitor (a displayed time will not be recorded on the video). In either case, the time code will be generated and the Time Code Out should be connected to the Audio In or Time Code In on the recorder. The GGA string from the GPS receiver is connected via a 3-mm (1/8-in.) stereo connector to the REM port. The port settings are 9600 baud, no parity, 8 data bits, and 1 stop bit. The sensor data from the notebook computer are connected to the COMM port via a similar connector. These are shown in Figure A7. The settings for this port are also 9600 baud, no parity, 8 data bits, 
and 1 stop bit. If SVHS video is used, a splitter is available to separate the chroma and lumina signals. If the GPS-3 is to be installed between the camera and the recorder, then two of these adapter/splitters are necessary. The lumina signals are connected through the GPS-3 while the chroma signals are connected together. An alternative method of installing the GPS-3 is to connect it between the VCR and the monitor, using the composite video output of the VCR.

\section{Video Camera}

The video camera currently used in this implementation of IDAS is the Sony CCD-TR700 High 8 camcorder (Figure A8). This camera is capable of providing both SVHS and composite video outputs. It also can provide audio outputs if required. The camera

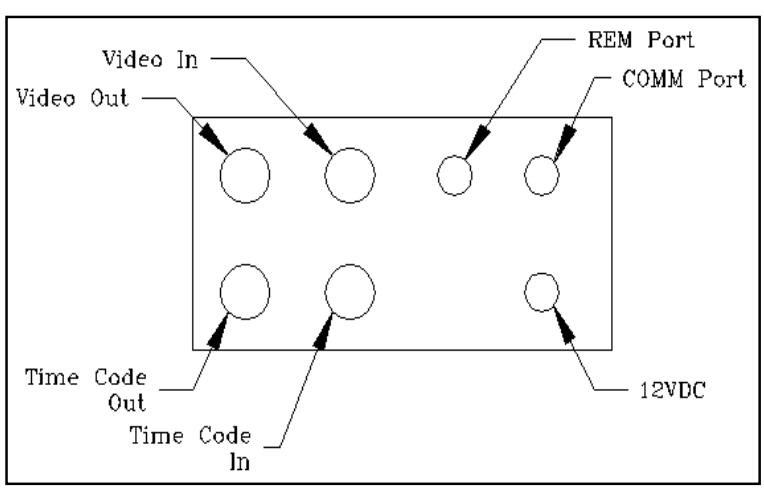

Figure A7. GPS-3 port schematic

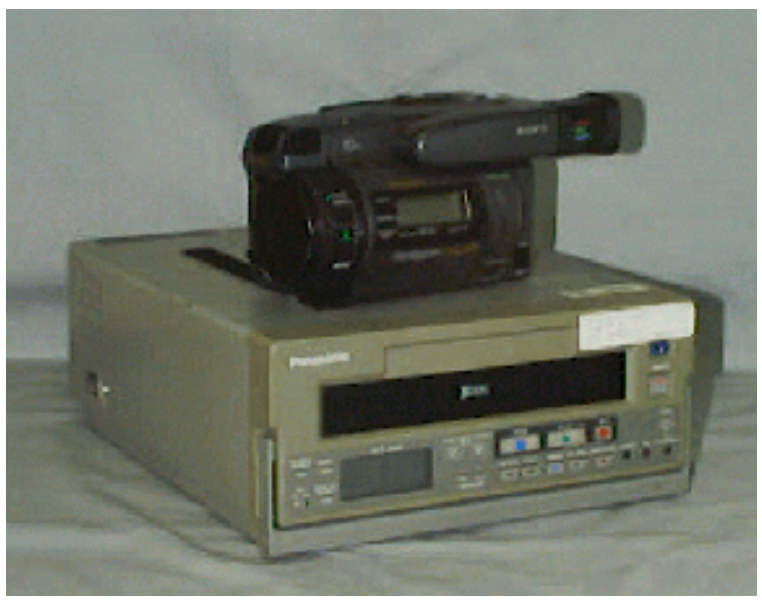

Figure A8. Sony CCD-TR700 and Panasonic AG-5700 normally is operated using the supplied 110-V a-c power supply; however, a 12-V d-c adapter is available. The camera may also operate on standard 8-mm style camcorder batteries. The last option is typically not used due to the lack of reliability of batteries. This camera is equipped with the ì Steady Shotî technology and automatic focus and gain controls. This camera is equipped with a 10x zoom feature also.

\section{Video Recorder}

The VCR used is the Pansonic AG-5700 (Figure A8). It can record in SVHS as well as standard VHS modes. It is a professional grade deck that is very portable and rugged. It has adjustable audio levels and two separate channels. It can record in 2-hour and 6-hour modes though normally imagery is recorded in the 2-hour mode. It also has adjustable tracking and audio dubbing capabilities. On the rear panel there are six switches (Figure A9). In the top left corner of the unit (looking at the back), there is an Auto Repeat Mode switch, which determines how the recorder responds during playback. It has three settings: Tape End, which will rewind the tape once it has reached the end of the tape; Video End, 


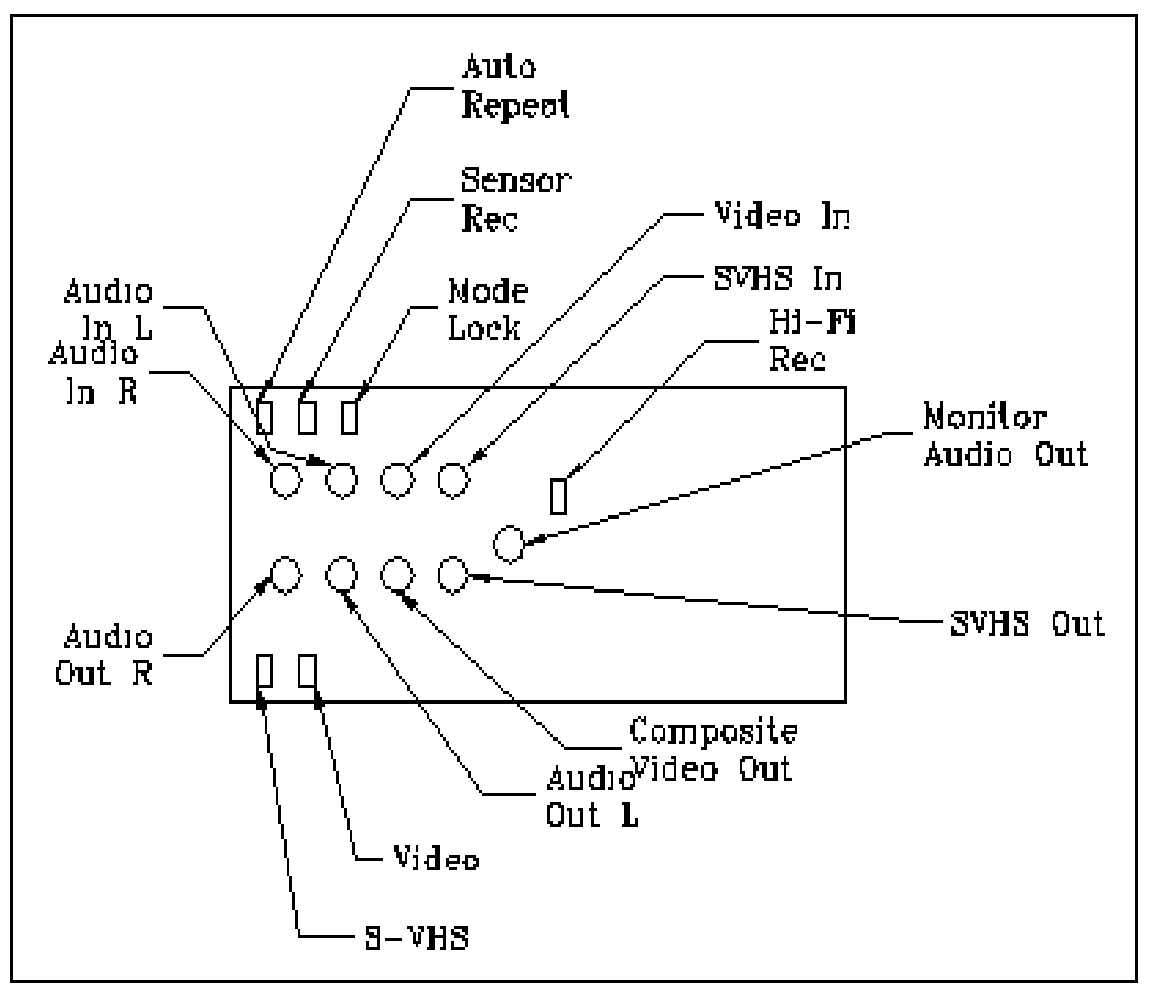

Figure A9. AG-5700 switches and input and output ports

which will cause the recorder to rewind at the conclusion of the recorded video; and Off. In either the Tape End or the Video End, the recorder will repeat the video once it has been rewound. In the Off setting, the recorder will rewind the tape and stop. The Off setting is normally used. The second switch is for Sensor Record mode (labeled Sensor Rec). In the On position, the recorder will automatically start recording once power is switched on. In the Off position, the recorder simply goes into standby operation, and this is the mode normally used. The third switch is labeled Mode Lock. With the mode enabled (switch in the On position) all front panel controls are locked out. This switch is also normally set to Off. In the lower left corner, there are two switches labeled SVHS and Video. The SVHS switch controls whether the unit is in SVHS mode or normal VHS mode. Normal VHS video tapes may be recorded in SVHS mode; however, this is not advisable since many VHS tapes may not be capable of properly preserving the more dense format. This switch is set to On when SVHS tapes and cameras are being used and Off when they are not. The Video switch setting determines which input port is used for the incoming video signal. In the SVHS setting, video is recorded from the SVHS In port. In the Line setting, video is recorded from the Video In port. The last switch is located to the right of the Monitor Audio Out and is labeled Hi-Fi Rec. This switch controls the mixing of the audio input channels. With the switch in the On position, audio channels remain separate as long as signals are fed to each channel. When one channel is silent (no incoming audio), then audio from the other channel is also stored on that track. With switch in the Off position, the audio is mixed on both channels. 


\section{Laser Rangefinder}

The laser rangefinder that has been used in conjunction with IDAS is the Laser Atlanta Advantage Laser (Figure A10). This laser is normally hand-held, but can be equipped with a tripod mount handle with a $1 / 4 \times 20$ threaded nut in the bottom. This handle may also be manufactured for use with an external $12-\mathrm{V}$ d-c power supply. This laser is connected to the data collector for the Trimble Pathfinder (TSC-1) via an RS-232 connection. The laser is configured for continuous update/output (while trigger pulled) and data are stored in the TSC- 1 at a $0.5-\mathrm{Hz}$ rate ( 1 record every 2 seconds). The laser can accurately measure range ( $\pm 152 \mathrm{~mm}(6 \mathrm{in}$.$) ) at ranges of up to$ $32,000 \mathrm{ft}$ without the use of a reflector on the target. The laser is also configured with an internal compass and tilt sensor similar to the TCM-2. The data stored in the TSC- 1 consist of the range, the compass direction, and the tilt of the laser along with the associated units. The laser can measure and transmit in either Non-SI or SI units. The principal disadvantage of this particular laser is that it makes the camera assembly very difficult to adjust and control. This is due to the high profile of the laser above the camera. Laser Atlanta also features customdesigned lasers that can be mounted attached to the camera tripod with a much lower profile (Figure A11). When acquiring data with very small tilt angles $(<5 \mathrm{deg})$, it is recommended that a laser be used to provide a more

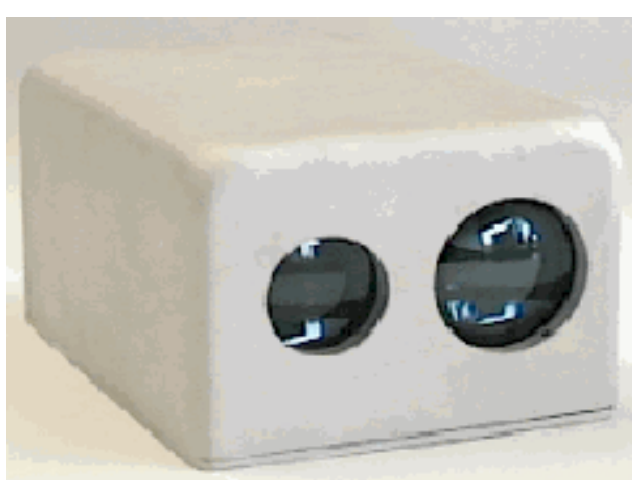

Figure A11. Example of Laser Atlanta custom laser accurate range than can be calculated with the imaging software. 


\section{Appendix B Accuracy Assessment}

Accuracy assessment of geo-referenced images collected by IDAS requires the complete knowledge of the accuracy of the positional instrumentation. The specific accuracy assessment utilized here will be to establish confidence intervals for the calculated centroid point of a captured video frame.

Table B1 presents the accuracy of the positional instrumentation as used in the IDAS system.

\begin{tabular}{|c|c|c|}
\hline \multicolumn{3}{|l|}{ Table B1 } \\
\hline Name & Precision & Accuracy \\
\hline Altimeter (microENCODER) & 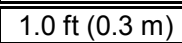 & 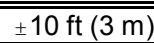 \\
\hline Global Positioning System (Trimble) & $0.01 \mathrm{~m}$ & $\pm 1.0 \mathrm{~m}$ \\
\hline Azimuth (Crossbow Gyroscope) & $0.1 \mathrm{deg}$ & $\pm 1.0 \mathrm{deg}$ \\
\hline Pitch/Tilt (Crossbow Gyroscope) & $0.1 \mathrm{deg}$ & $\pm 1.0 \mathrm{deg}$ \\
\hline
\end{tabular}

The centroid of the frame center is calculated as a function of horizontal distance and azimuth. The horizontal distance is determined by multiplying the height of the sensor (above ground level) by the tangent of the absolute value of the pitch (Equation B1).

$$
D=\Delta z / \tan \left[\operatorname{abs}\left(\theta_{t}\right)\right]
$$

where $D$ is distance, $\Delta z$ is height of the instrument above the ground, and $\theta_{\mathrm{t}}$ is the degree of the pitch. The confidence interval is calculated as

$$
U_{D}^{2}=\left(\frac{\partial D}{\partial t} U_{t}\right)^{2}+\left(\frac{\partial D}{\partial z} U_{Z}\right)^{2}
$$

and performing the necessary partial derivatives provides

$$
U_{D}^{2}=\left\{\frac{-z}{\tan (t)^{2}}\left[1+\tan (t)^{2}\right] U_{t}\right\}^{2}+\left[\frac{1}{\tan (t)} U_{z}\right]^{2}
$$


where $U_{D}$ is the confidence interval of the calculated distance. Used in an example, let the height above the ground be $94 \mathrm{~m}(307 \mathrm{ft})$, sensor pitch be $-15.0 \mathrm{deg}$, then the calculated distance is $349 \pm 14 \mathrm{~m}(1,145.7 \pm 45.2 \mathrm{ft})(4$ percent error). At the same height and a sensor pitch of $-10.0 \mathrm{deg}$, the calculated distance and the interval would be $530.7 \pm 24.4 \mathrm{~m}(1,741.1 \pm 80.1 \mathrm{ft})(4.5$ percent error). The confidence interval dramatically increases as the pitch approaches the horizon and altitude increases.

The positional coordinates are calculated using the distance and the azimuth measurement of the sensor.

$$
\begin{gathered}
X_{c}=\sin (a) D+X_{o} \\
Y_{c}=\cos (a) D+Y_{o}
\end{gathered}
$$

and the confidence intervals are calculated similarly as before:

$$
U_{X_{c}}^{2}=\left(\frac{\partial X_{c}}{\partial a} U_{a}\right)^{2}+\left(\frac{\partial X_{c}}{\partial D} U_{D}\right)^{2}+\left(\frac{\partial X_{c}}{\partial X_{o}} U_{X_{o}}\right)^{2}
$$

Performing the necessary partial derivatives provides

$$
U_{X_{c}}^{2}=\left[\cos (a) \cdot D \cdot U_{a}\right]^{2}+\left[\sin (a) \cdot U_{D}\right]^{2}+\left[U_{X_{o}}\right]^{2}
$$

and similarly for the $Y_{c}$ confidence interval:

$$
U_{Y_{c}}^{2}=\left[\sin (a) \cdot D \cdot U_{a}\right]^{2}+\left[\cos (a) \cdot U_{D}\right]^{2}+\left[U_{Y_{o}}\right]^{2}
$$

Applying these in an example using the following parameters:

$$
\begin{aligned}
\Delta z & =307.0 \\
\theta_{t} & =15.0 \\
D & =1,145.7 \mathrm{ft} \\
U_{D} & = \pm 45.2 \\
a & =110 \mathrm{deg}
\end{aligned}
$$

and applying Equations B6 and B7, the confidence intervals for the calculated X and $Y$ coordinates are \pm 12.9 and $4.86 \mathrm{~m}( \pm 42.4$ and $\pm 15.96 \mathrm{ft})$, respectively.

When the azimuth is changed to 45 degrees, the $\mathrm{X}$ and $\mathrm{Y}$ confidence intervals are both $\pm 9.7 \mathrm{~m}(31.9 \mathrm{ft})$. 


\section{Appendix C System Costs and Acquisition}

IDAS, as developed, costs approximately $\$ 25,000$ for a single camera system. These costs are broken down in Table $\mathrm{C} 1$.

\begin{tabular}{|c|c|}
\hline \multicolumn{2}{|l|}{$\begin{array}{l}\text { Table C1 } \\
\text { System Costs }\end{array}$} \\
\hline Item & Cost \\
\hline GPS Receiver & $\$ \$ \$ 10,000$ \\
\hline Compass & $\$ 900$ \\
\hline Gyroscope & $\$ 4,000$ \\
\hline Altimeter & $\$ 1,200$ \\
\hline Camera & $\$ 1,500$ \\
\hline Video Recorder & $\$ 1,200$ \\
\hline Video Encoder/Decoder & $\$ 1,500$ \\
\hline Notebook Computer and Accessories & $\$ 2,500$ \\
\hline Total System Cost & $\$ 22,800$ \\
\hline
\end{tabular}

The IDAS software may be acquired free of charge by contacting the authors at:

U.S. Army Engineer Research Development Center ATTN: CEERD-EE-C (Mr. Charles Hahn/Mr. Jerrell Ballard) 3909 Halls Ferry Road

Vicksburg, MS 39180-6199

or by e-mail at hahnc@erdc.wes.army.mil or ballard@erdc.wes.army.mil. 


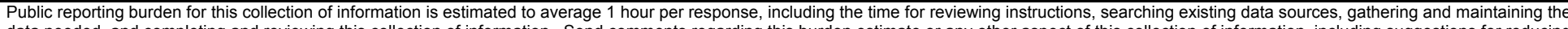

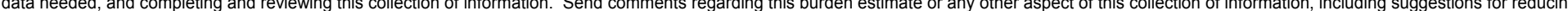

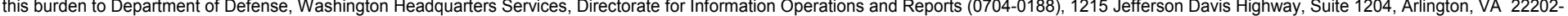

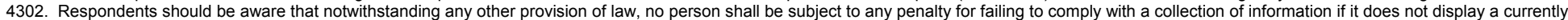
valid OMB control number. PLEASE DO NOT RETURN YOUR FORM TO THE ABOVE ADDRESS

\begin{tabular}{l|l|l} 
1. REPORT DATE (DD-MM-YYYY) & 2. REPORT TYPE & 3. DATES COVERED (FrOm - To)
\end{tabular}

September 2001

4. TITLE AND SUBTITLE

Final report

Image Data Acquisition System (IDAS) User's Guide

and Technical Documentation

5a. CONTRACT NUMBER

6. AUTHOR(S)

5b. GRANT NUMBER

5c. PROGRAM ELEMENT NUMBER

Charles D. Hahn, Jerrell R. Ballard, Jr.

5d. PROJECT NUMBER

5e. TASK NUMBER

5f. WORK UNIT NUMBER

7. PERFORMING ORGANIZATION NAME(S) AND ADDRESS(ES)

8. PERFORMING ORGANIZATION REPORT NUMBER

U.S. Army Engineer Research and Development Center

Environmental Laboratory

ERDC/EL TR-01-27

3909 Halls Ferry Road

Vicksburg, MS 39180-6199

9. SPONSORING / MONITORING AGENCY NAME(S) AND ADDRESS(ES)

10. SPONSOR/MONITOR'S ACRONYM(S)

U.S. Army Corps of Engineers

Washington, DC 20314-1000

11. SPONSOR/MONITOR'S REPORT NUMBER(S)

12. DISTRIBUTION / AVAILABILITY STATEMENT

Approved for public release; distribution is unlimited.

\section{SUPPLEMENTARY NOTES}

\section{ABSTRACT}

Image data collection activities are typically limited to the use of normal aerial photography techniques. This approach is often expensive and requires extensive ground control. The imagery is limited in the ability to "see" the sides of features or underneath the tree canopy. The Image Data Acquisition System (IDAS) provides a low-cost alternative to traditional aerial photography. IDAS couples inexpensive video technology with Global Positioning Satellite (GPS) technology to provide referenced video imagery in real time with minimal requirements for ground control and rigid flight plans. Additional sensors (digital compass, gyroscope, and altimeter) provide camera geometry regardless of the platform path. IDAS is a portable system that can be easily deployed on multiple platforms (aircraft, boats, or ground vehicles). The data processing system couples the imagery, position, and camera geometry data with a terrain database to provide approximate ground locations for features imaged.

15. SUBJECT TERMS

Aerial photography GPS

16. SECURITY CLASSIFICATION OF:

a. REPORT

UNCLASSIFIED b. ABSTRACT

UNCLASSIFIED
Image data collection Video imagery

Remote sensing

7. LIMITATION OF ABSTRACT

c. THIS PAGE

UNCLASSIFIED

\begin{tabular}{c|l}
$\begin{array}{l}\text { 18. NUMBER } \\
\text { OF PAGES }\end{array}$ & \begin{tabular}{l} 
19a. NAME OF RESPONSIBLE PERSON \\
\cline { 2 - 2 } 45
\end{tabular} \\
\cline { 2 - 2 } & $\begin{array}{l}\text { 19b. TELEPHONE NUMBER (include area } \\
\text { code) }\end{array}$ \\
\end{tabular}

Standard Form 298 (Rev. 8-98)

Prescribed by ANSI Std. 239.18 